UNIVERSIDADE DE BRASÍLIA

FACULDADE DE EDUCAÇÃO FÍSICA

PROGRAMA DE PÓS-GRADUAÇÃO STRICTO SENSU EM EDUCAÇÃO FÍSICA

ASSOCIAÇÃO ENTRE A COMPOSIÇÃO CORPORAL,

FADIGA E SONOLÊNCIA EXCESSIVA DIURNA EM

INDIVÍDUOS COM DOENÇA DE PARKINSON

Candice Alvarenga Coelho 


\section{ASSOCIAÇÃO ENTRE A COMPOSIÇÃO CORPORAL, FADIGA E SONOLÊNCIA EXCESSIVA DIURNA EM INDIVÍDUOS COM DOENÇA DE PARKINSON}

Candice Alvarenga Coelho

Dissertação de mestrado apresentada ao Programa de Pós-graduação Stricto Sensu da Faculdade de Educação Física da Universidade de Brasília como requisito para a obtenção do Grau de Mestre em Educação Física.

ORIENTADOR: PROF. DR. RICARDO JACÓ DE OLIVEIRA 


\section{EPÍGRAFE}

"Somos todos anjos de uma asa só, e somente podemos voar com a ajuda um dos outros."

Luciano de Crescenzo 


\section{DEDICATÓRIA}

Dedico este trabalho - de todo o coração - a aqueles que muito me ajudaram ao longo desta jornada: meu esposo Carlos Henrique, meus filhos maravilhosos Maria Clara, Pedro Henrique e João Vítor, meu querido mestre Dr. Roberto Low, e, para meus pais, José Florêncio e Maria do Amparo, que sem eles eu nada seria. 


\section{AGRADECIMENTOS}

- Agradeço primeiramente ao carinho e amor de todos os meus queridos pacientes que se prontificaram a participar do estudo, assim como aos de outros colegas e que fazem parte do grupo de atividade física para doenças neurodegenerativas da FEF, seus familiares e cuidadores;

- Aos meus colegas da pós-graduação: Ariel, Rita, Samuel, Juliana, Lorena, Hugo, Tácio e Bruno, obrigado por dividirem os bons e maus momentos. Filipe Dinato, em especial, pela generosidade e auxílio nesta reta final;

- Agradeço à generosidade, paciência e atenção de minha colega de pósgraduação e amiga, Ritielli Valeriano, obrigado pela ajuda inestimável especialmente neste último ano. Sem você teria sido muitíssimo mais difícil;

- Ao Professor Rinaldo Mezzarane por repassar seu infindável conhecimento neurofisiológico, e, ao seu pupilo Tiba por sua facilidade em "explicar o grego" e tornar o termo "o saber deve ser compartilhado" uma prática.

- Ao Professor Vinicius Maldoner pelas excelentes aulas e em especial pela compreensão e apoio durante a doença de meu pai.

- A painho por ter sobrevivido à endocardite e ter sido um excelente paciente, exceto nos últimos dias, quando não escutava o despertador e deixava passar o horário do antibiótico para dar uns minutos de descanso a sua filha.

- A todos os funcionários da FEF por sua prestatividade, atenção e carinho. Um agradecimento especial à equipe da secretaria de pós graduação - aos que se foram e aos que estão - Alba, Quélbia, Tiago e Henrique.

- Aos chefinhos no consultório, Dra Ana e Dr Roberto Low, e minha colega e amiga, Dra Cristiane Low, que tanto ajudaram nesta empreitada, no suporte aos pacientes durante munha ausência.

- Às secretárias fofinhas da clínica Low, Míriam, Dáuria e Neide, que se desdobraram em desmarcar e remarcar os pacientes no período desta pósgraduação.

- Ao apoio da equipe da Pneumologia e Medicina do Sono do Hospital Universitário de Brasília - HUB, em especial ao chefe, Dr Marcelo Palmeira, que incentivou essa pesquisa. 


\section{RESUMO}

A doença de Parkinson (DP) é um processo neurodegenerativo conhecido por suas características clássicas: tremor, rigidez, bradicinesia e instabilidade postural. Entretanto, apesar da DP ser classicamente descrita como desordem do movimento, sintomas não motores (SNM) também fazem parte da doença, a exemplo da fadiga e da sonolência excessiva diurna (SED). As evidências dos SNM comprometendo também a execução das atividades da vida diária são inegáveis, porém é o declínio motor que é priorizado nas avaliações médicas. O prejuízo motor se traduz em redução da massa e força muscular, velocidade e equilíbrio, em especial naqueles com a forma rígida (FR) que possui sintomas axiais e têm predomínio de bradicinesia. A forma tremulante $(\mathrm{FT})$ teria curso evolutivo mais benigno em relação à função motora e menor incidência de declínio cognitivo na fase avançada. As modificações da composição corporal, incluindo redução da massa muscular com substituição por tecido gorduroso fazem parte do processo natural do envelhecimento, porém são mais frequentes nos portadores da DP. Além disso, SNM como fadiga e SED comprometem significativamente a realização de exercícios, fato que contribui para progressão da sarcopenia. Objetivo: Analisar a associação entre composição corporal, fadiga e SED em pacientes acometidos pela DP. Métodos: Fizeram parte do estudo 48 portadores de DP que foram submetidos à avaliação neurológica e classificados como sendo 26 FR e 22 FT nos estágios entre 1 e 3 de HY. Todos foram avaliados através das escalas de Severidade da Fadiga e de Sonolência de Epworth, sendo que esta última escala foi também mensurada por familiares de 23 acometidos. A composição corporal foi medida através da densitometria por emissão de raios $X$ de dupla energia (DXA). Resultados: 31 indivíduos apresentaram fadiga (64,5\%), destes 21 possuíam a FR. A SED acometeu $21(43,75 \%)$ dos 48 participantes, sendo $13 \mathrm{com}$ a FR. Os dois SNM juntos foram detectados em 17 sujeitos (35,4\%), 13 FR e 4 FT. Os indivíduos com a FR apresentaram maior percentual de gordura e fadiga, além de maior Índice de Massa Corporal (IMC). Os familiares observaram maior sonolência que a identificada pelos participantes, sendo esta percepção estatisticamente significativa. Conclusão: verificou-se uma relação significante entre a forma rígida da DP com maiores níveis de fadiga e percentual de gordura corporal e maior IMC. Além disso verificou-se que a percepção de SED foi maior naqueles com rigidez predominante. Foi observada uma divergência significante entre a percepção da sonolência apresentada pelos portadores da doença e a observação objetiva de seus familiares.

Palavras-chave: Doença de Parkinson; Sonolência Excessiva Diurna; Fadiga; Composição corporal; DXA; Densitometria por emissão de raios $\mathrm{X}$ de dupla energia. 


\begin{abstract}
Parkinson's disease (PD) is a neurodegenerative process known for its classical features: tremor, rigidity, bradykinesia and postural instability. However, despite the fact that PD is classically described as a disorder of movement, non-motor symptoms (NMS) are also part of the disease, such as fatigue and excessive daytime sleepiness (EDS). Evidence of NMS also compromising the performance of daily life activities are undeniable, but the decline of motor functions is always prioritized in routine medical evaluations. The motor impairment translates into reduction of mass, muscular strength, speed and balance, particularly in those individuals with prevalence of rigid form symptoms (RF) which also have axial symptoms and a predominance of bradykinesia. The tremor-dominant form (TF) would evolve in a more benign way on the motor aspect and show less cognitive decay in the advanced phase. The changes in body composition, including the reduction of muscle mass with replacement by fat tissue are part of the natural aging process, however they are more significant in those afflicted by PD. In addition, NMS as fatigue and sleepiness significantly compromise the performance of exercises, a fact that contributes to sarcopenia. Objective: To analize the association of body composition, fatigue and EDS in patients suffering from PD. Methods: Participants were 48 patients with PD, $26 \mathrm{RF}$ and $22 \mathrm{TF}$, in stages beetween 1 to 3 of HY scale. All of them were evaluated by the Epworth scales of severity of fatigue and sleepiness and this last one was also applied to relatives of 23 patients to check their perception of the patient's sleepiness. Body composition was measured by densitometry by issuing dual-energy x-ray absorptiometry (DXA). Results: 31 subjects had fatigue (64.5\%) and 21 of them had the RF. The EDS occurred in 21 $(43.75 \%)$ of the 48 participants, 13 with the RF. Both NMS were simultaneously detected in 17 subjects (35.4\%), 13 RF and 4 TF. Individuals with RF had a higher percentage of fat and fatigue as well as increased body mass index (BMI). The relatives reported more drowsiness perception than the patients, a statistically significant amount. Conclusion: a significant correlation between the rigid form of PD with higher levels of fatigue and percentage of body fat and BMI was verified. Furthermore it was found that the perception of EDS was higher in those subjects with predominant rigidity. A significant divergence between the perception of sleepiness presented by the carriers of the disease and the objective observation of their companions was observed.
\end{abstract}

Keywords: Parkinson's disease; Excessive Daytime sleepiness; Fatigue; Body composition; DXA; Densitometry by dual-energy x-ray absorptiometry. 


\section{SUMÁRIO}

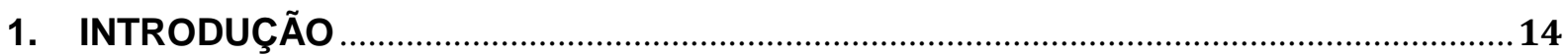

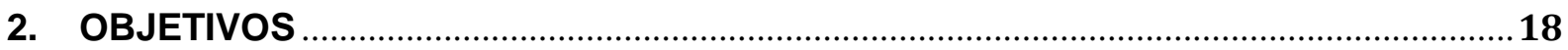

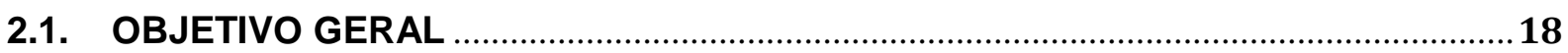

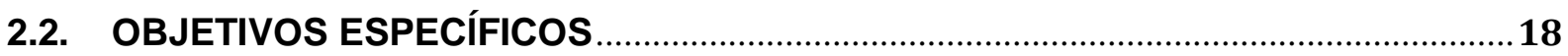

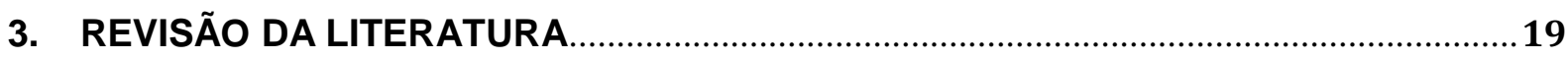

3.1. HISTÓRICO E EPIDEMIOLOGIA DA DOENÇA DE PARKINSON .............................19

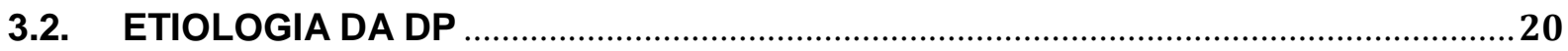

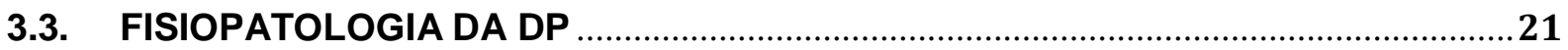

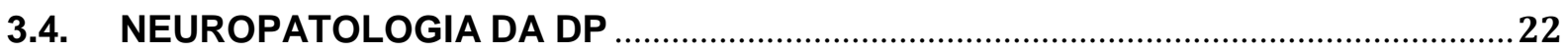

3.5. CORRELAÇÕES CLÍNICO-PATOLÓGICA DOS SUBTIPOS MOTORES ..................27

3.6. MANIFESTAÇÕES CLÍNICAS DA DOENÇA DE PARKINSON .................................28

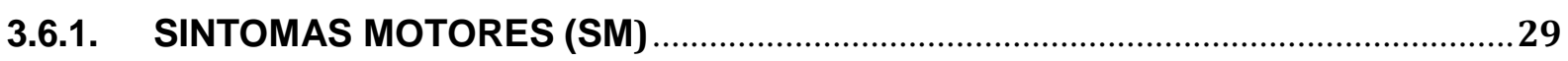

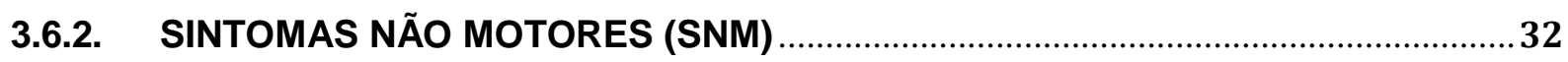

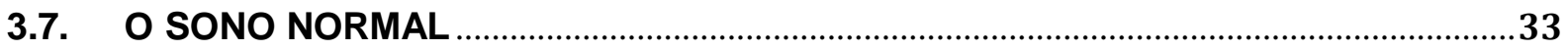

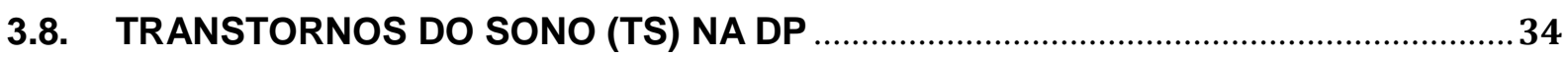

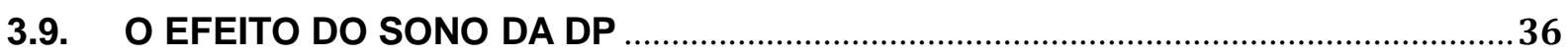

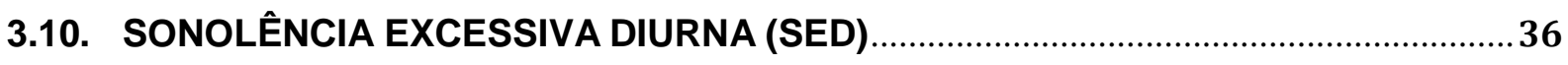

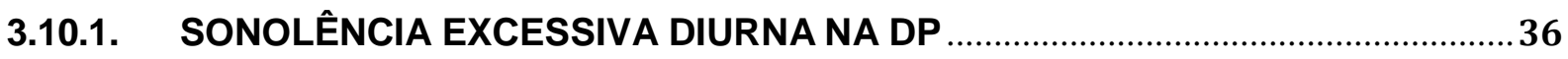

3.11. FADIGA

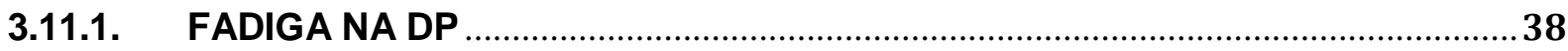

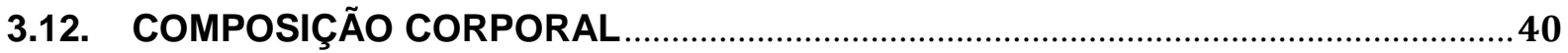

3.12.1. COMPOSIÇÃO CORPORAL E ENVELHECIMENTO …......................................40

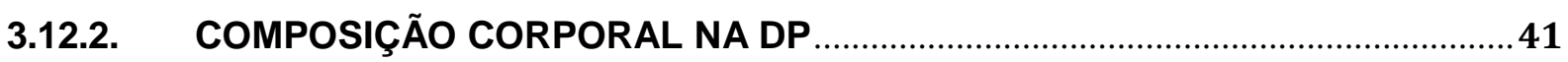

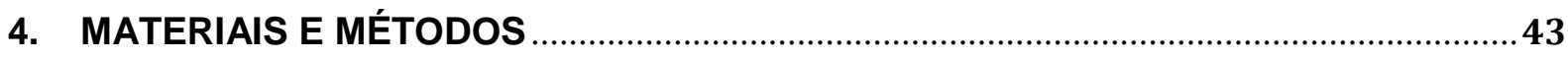

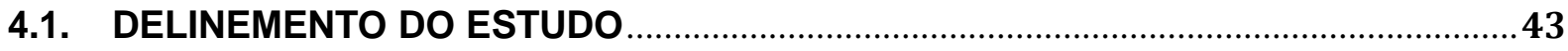

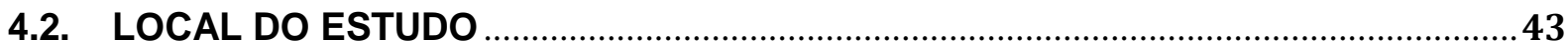

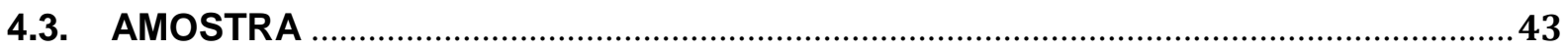

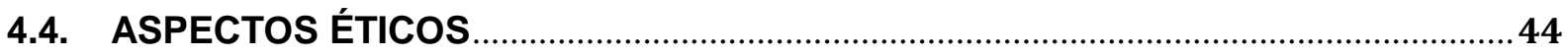

4.5. PROCEDIMENTO PARA A COLETA DE DADOS ….................................................44

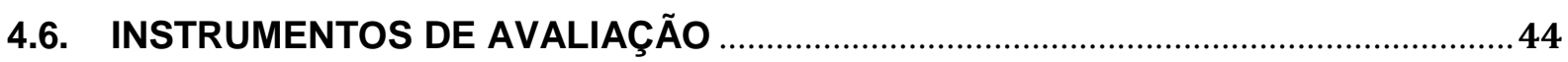


4.7. TRATAMENTO ESTATÍSTICO 48

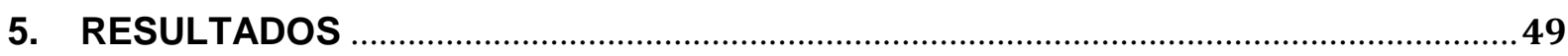

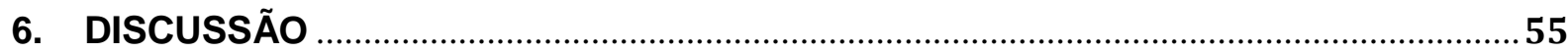

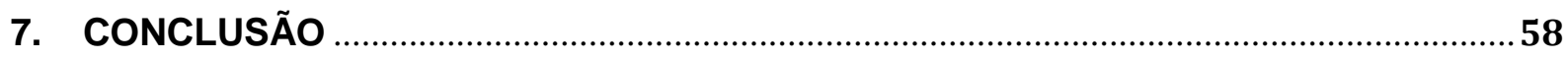

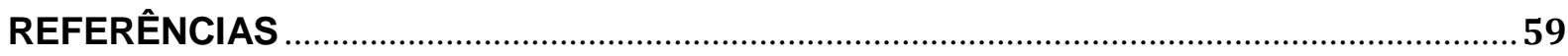

APÊNDICE A

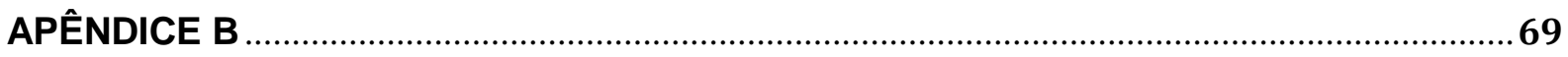

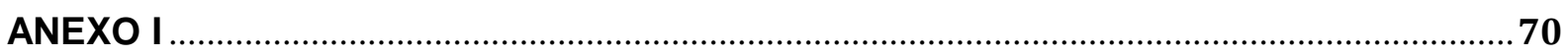

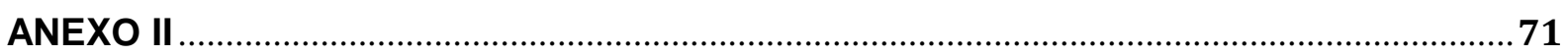

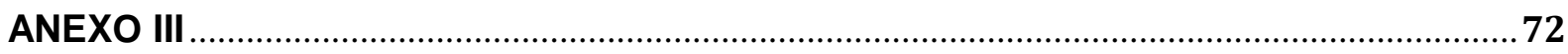




\section{LISTA DE FIGURAS}

Figura 1 - Estágios relacionados ao desenvolvimento da DP: regiões atingidas pelas lesões com CL e neuritos de Lewy, que se iniciam na medula oblonga (núcleo dorsal do nervo vago - IX e $X$ ) e bulbo olfatório seguindo pelo tronco encefálico até o córtex cerebral (direção das flechas). Fonte: Cell Tissue Res. 2004 Oct;318(1):12134.

Figura 2 - The Braak stages of PD. Fonte: Doty RL (2012) Nature Reviews Neurology 8, 329-339.

Figura 3 - Sinais na apresentação dos SM da DP. Extraído de www.ecsaweb.com 


\section{LISTA DE TABELAS}

Tabela 1 - Características da amostra agrupadas por sexo expressas em média e desvio padrão.

Tabela 2 - Características da amostra agrupadas pelo nível de acometimento expressas em média e desvio padrão

Tabela 3 - Características da amostra agrupadas por forma rígida (FR) ou tremulante (FT) expressas em média e desvio padrão

Tabela 4 - Variáveis de composição corporal expressas em média e desvio padrão. .51

Tabela 5 - Escores de Sonolência e Fadiga expressas em média, desvio padrão, mediana, mínimo e máximo.

Tabela 6 - Variáveis de composição corporal, sonolência e fadiga diferenciadas para FR ou FT expressas em média e desvio padrão.

Tabela 7 - Relações entre fadiga, sonolência e composição corporal demonstradas em Rô de Spearman e significância 52

Tabela 8 - Percepção de sonolência sentida pelo paciente e relatada pelo familiar. .53

Tabela 9 - Relação entre sonolência percebida pelo familiar de 23 sujeitos com a composição corporal demonstradas em Rô de Spearman e significância

Tabela 10 - Características dos 23 indivíduos que possuíam o relato do familiar, expressos em média e desvio padrão

Tabela 11 - Variáveis de composição corporal, sonolência e fadiga diferenciadas por rígidos ou tremulantes expressas em média e desvio padrão. 


\section{LISTA DE ABREVIATURAS E SIGLAS}

$\begin{array}{ll}\text { AD } & \text { Autossômica Dominante } \\ \text { AR } & \text { Autossômica Recessiva } \\ \text { AVDs } & \text { Atividades da Vida Diária } \\ \text { CL } & \text { Corpos de Lewy } \\ \text { DA } & \text { Dopamina } \\ \text { DMO } & \text { Densidade Mineral Óssea } \\ \text { DP } & \text { Doença de Parkinson }\end{array}$

DXA Dual-energy X-ray Absorptiometry

ESE Escala de Sonolência de Epworth

ESF Escala da Severidade da Fadiga

FR Forma Rígida

FT Forma Tremulante

GPi Glopo Pálido interno

$\mathrm{GPe} \quad$ Globo Pálido externo

H\&Y Hoehn \& Yahr

IMC Índice de Massa Corporal

QV $\quad$ Qualidade de Vida

MPM Movimentos Periódicos dos Membros

NMDV Núcleo Motor Dorsal do Vago

NTs Neurotransmissores

SAOS Síndrome da Apnéia Obstrutiva do Sono

SED Sonolência Excessiva Diurna

SM Sintomas Motores

SNM Sintomas Não Motores 
NB Núcleos da Base

SN Substância Negra

SNc Substância Negra pars compacta

SNr Substância Negra pars reticular

SNC Sistema Nervoso Central

REM Rapid Eye Movement (Movimentos Oculares Rápidos)

TCSR Transtorno Comportamental do Sono REM

UPDRS Unified Parkinson's Disease Rating Scale 


\section{INTRODUÇÃO}

A Doença de Parkinson (DP) clinicamente se caracteriza pela tétrade de tremor em repouso, rigidez, bradicinesia com hipocinesia e perturbações do equilíbrio, com a particularidade de se iniciar de forma dimidiada (HUGHES et al, 1992). Embora seja identificada como um distúrbio do movimento, a DP está associada a uma gama de sintomas não-motores (SNM) descritos no estudo de James Parkinson em 1817, como transtornos do sono (TS), depressão, psicose, alucinações e disfunção cognitiva. Muitas dessas manifestações, principalmente os TS, podem preceder em décadas o diagnóstico da DP ou ocorrer nos estágios iniciais (ADLER, 2005; POEWE, 2008; CHAUDHURI, NAIDU, 2008).

Nas últimas décadas estudos clínicos, epidemiológicos e histopatológicos disponibilizaram mais evidências quanto a existência da fase pré-motora (BRAAK et al, 2004) com os distúrbios do sono sendo mais valorizados (TOLOSA et al, 2007). Outro aspecto relevante é que os efeitos colaterais dos medicamentos, apesar de promoverem benefícios nas manifestações motoras, podem induzir ou agravar alguns SNM como hipotensão ortostática, alucinações, fadiga, sonolência excessiva diurna (SED), e assim interferir de forma significativa na capacidade funcional destes indivíduos (ADLER, 2005; POEWE, 2008). Apesar da prevalência, os SNM, especialmente os TS, são subestimados na prática clínica, o estudo de Shulman e colaboradores (2002) identificou que em consultas de rotina as alterações de sono não eram identificadas pelos neurologistas em mais de $40 \%$ das vezes.

A exata prevalência dos distúrbios do sono na DP é desconhecida, todavia, as queixas relatadas pelos indivíduos acometidos chegam a até $90 \%$ dos casos (TRENKWALKDER, 1998), sendo importante fator preditivo de má qualidade de vida (SCARAVILLI, 2003). Os TS que ocorrem no período noturno com maior frequência são: insônia, sono fragmentado, transtorno comportamental do sono REM (Rapid Eye Movement) (TCSREM), síndrome da apnéia obstrutiva do sono (SAOS) e movimentos periódicos dos membros (MPM). Durante o período de vigília são frequentes a SED, sleep attacks (ataques de sono) e a síndrome das pernas inquietas (SPI). Tais distúrbios contribuem para deterioração das funções cognitivas, 
e, de forma simultânea, este declínio também contribui para a piora do quadro motor (NOCERA et al, 1999; ALVES et al, 2010).

Entre os SNM, a fadiga pode ser um importante determinante da qualidade de vida $(Q V)$ e incapacidade física na $P D$, e é subestimada em termos de seu impacto negativo sobre o bem-estar do paciente; frequentemente é considerada pelos pacientes com DP como um dos sintomas mais incapacitantes que afetam suas atividades de vida diária (AVDs) e a QV (HALAVLIKOVA et al, 2008). Em estudos com portadores de DP e grupos-controle sua prevalência variou de 35.4 a 59.1\% (DEL SORBO, ALBANESE, 2012; WEN et al, 2012; FABBRINI et al, 2013). Haggel e Brundin (2009) indicaram que a fadiga também poderia ser uma manifestação precoce ou mesmo pré-motora da DP (HAGELL, BRUNDIN, 2009).

Em um estudo realizado em 2014, com 402 portadores da DP, inferiu-se que a fadiga foi sintoma comum nos pacientes ambulatoriais tendo sido considerada significante em cerca de um terço deles. A análise mostrou que a presença de fadiga severa foi associada a aumento da gravidade da doença, pior qualidade de vida, comportamentos sociais e psicológicos piores, maior severidade de sintomas depressivos, e maior prevalência de distúrbios do sono noturno e SED (STROCCHI et al, 2014). A constatação da associação fadiga, SED e depressão também foi verificada no estudo de Goulart e colaboladores (2009), quando 70\% dos indivíduos com DP, preenchiam critérios para fadiga.

$\mathrm{Na}$ DP a SED ocorre em cerca de $50 \%$ dos acometidos e tem impacto relevante para a QV podendo ser mais incapacitante do que os sintomas motores em alguns indivíduos (KINE et al, 2011). A SED também pode preceder os sintomas parkinsonianos clássicos, conforme observado em um estudo asiático, onde homens com SED acompanhados a longo prazo, tiveram a incidência de DP três vezes maior quando comparado a aqueles sem tal sintoma, persistindo a associação entre o surgimento da SED e o risco para o desenvolvimento da DP após análise de outros fatores (ABBOT et al, 2005). A SED na DP pode ser devido aos TS, efeitos colaterais de medicações, depressão, primária por progressão da disfunção do tronco cerebral, ou ainda que esta possa ter seus sintomas piorados pelos itens secundários mencionados anteriormente (KINE et al, 2011). 
Observa-se que a prevalência de incapacidade e dependência funcional é significativa em idosos e está intimamente associada à redução da massa muscular, que ocorre até mesmo nos saudáveis, mas que é mais significativa naqueles que possuem algumas doenças neurodegenerativas como a DP e o Mal de Alzheimer (MAETZLER, DREY, JACOBS, 2015). A perda de massa magra e força muscular é responsável pela redução da mobilidade, capacidade funcional e dependência, e quando associada à síndrome da fragilidade, gera custos econômicos e sociais significativos (FOX et al, 2000; CRUZ-JENTOFT et al, 2010). A presença de SED pode ser um agravante para as situações de risco citadas (NAMI, 2012).

A situação dos indivíduos acometidos pela DP deve ser considerada no contexto da sarcopenia como tendo contribuições negativas adicionais em relação à gravidade da doença e no tratamento dopaminérgico. Esses fatores incluem perturbação da regulação metabólica hipotalâmica, alteração do gasto energético através de tremor, rigidez, discinesia, nível de atividade física, perturbações do sono, e, alteração da quantidade de ingestão de alimentos que pode ser prejudicada por perturbação da deglutição, distúrbios gastrointestinais e alteração do comportamento alimentar que podem acometer indivíduos com DP (KISTNER, LHOMMÉE, KRACK, 2014).

A forma rígida da DP (FR), ao contrário da tremulante ( $F T)$ é aquela que apresenta mais componentes axiais, com hipocinesia/bradicinesia, deficiências na marcha (variabilidade da passada) e instabilidade postural (JANKOVIC, 2008) com consequente diminuição do equilíbrio, representando um risco aumentado de quedas (FINDLEY et al, 2002; WILLIAMS, WATT, LEES, 2006; LATT, 2006). Além disso, cair pode desencadear um círculo vicioso, onde o medo de outras quedas reduz a locomoção dos sujeitos e a realização de exercícios físicos, que por sua vez pode causar a sarcopenia, osteoporose, perda de independência, isolamento social, e redução das AVDs (FINDLEY et al, 2002; LATT, 2006; CRUZ-JENTOFT et al, 2010).

Ressalta-se que apesar dos estudos que envolvem a compreensão da fadiga e da SED na DP, várias são as lacunas que relacionam esses SNM com a composição corporal nos indivíduos acometidos. As poucas publicações têm o objetivo principal de identificar as medidas de composição corporal (TOTH, 
FISHMAN, POEHLMAN, 1997; REVILLA et al, 1998; PETRONI et al, 2003; FERNANDEZ et al, 2007) e duas correlacionam essas mensurações com os níveis séricos de vitamina D (PETRONI et al, 2003; FERNANDEZ et al, 2007). Porém, até o presente momento não há registro de publicações que tratam da influência dos subtipos motores rígido e tremulante na modificação da composição corporal, bem como a influência da composição corporal sobre a fadiga e a SED nos indivíduos com DP e suas possíveis implicações clínicas. Além disso, a abordagem com os familiares de indivíduos quanto à investigação da SED, apesar de recomendado na anamnese (NAMI, 2012) ainda não foi tema de pesquisa na DP até o presente momento.

A busca em preencher essas lacunas são a razão desta pesquisa. 


\section{OBJETIVOS}

\subsection{OBJETIVO GERAL}

Analisar a associação entre a composição corporal e os sintomas não motores - Fadiga e Sonolência Excessiva Diurna (SED) - em portadores da Doença de Parkinson (DP).

\subsection{OBJETIVOS ESPECÍFICOS}

- Analisar a composição corporal em acometidos pelos subtipos motores - rígido e tremulante - da Doença de Parkinson (DP);

- Verificar a presença de SED em indivíduos com DP, por meio da percepção do portador da doença e de seu familiar. 


\section{REVISÃO DA LITERATURA}

\subsection{Histórico e Epidemiologia da Doença de Parkinson}

A Doença de Parkinson (DP) é reconhecida como entidade nosológica desde a publicação do estudo An Essay on Shaking Palsy. Neste ensaio o autor James Parkinson acompanhou seis pacientes entre 50 e 72 anos que apresentavam "movimentos tremulantes involuntários, diminuição da força muscular, tendência em inclinação para frente e alteração da marcha" (PARKINSON, 1817). As pesquisas dos sintomas clínicos foram aprofundadas quatro décadas depois pelo neurologista francês Jean-Martin Charcot, que confirmou o estudo de James Parkinson e modificou o nome da patologia para Mal de Parkinson. Charcot descreveu também o espectro clínico da enfermidade e distinguiu dois tipos motores de manifestações da doença: a forma tremulante e a rígido-acinética, além de melhor caracterizar o tremor da DP. Descreveu também as disautonomias e outras características como a micrografia e a disartria. Em 1895 Édouard Brissaud levantou a hipótese de que uma lesão na substância negra ( $S N$ ) poderia ser a base anatômica da moléstia (GOEDERT et al, 2013).

Atualmente o conhecimento sobre sua existência está difundido, pois, é a segunda doença neurodegenerativa mais prevalente do mundo, sendo superada apenas pelo Mal de Alzheimer, e acomete todos os grupos étnicos e classes socioeconômicas. É uma doença complexa cujo fatores como idade e sexo influenciam na chance de desenvolver a patologia; e como em outras doenças degenerativas tem como principal fator de risco a idade avançada - apenas $10 \%$ dos portadores da doença têm idade inferior a 45 anos (LEES, HARDY, REVESZ, 2009). Afeta uma em cada 100 pessoas com idade superior a 60 anos, e, quatro em cada 100 pessoas acima de 80 anos de idade nos países industrializados (SCHENKMAN et al, 2012). No Brasil, um estudo com base populacional identificou a prevalência de 3.3\% para a DP em indivíduos com mais de 60 anos (BARBOSA et al, 2006). Em relação ao gênero, alguns estudos mostram até cinco vezes mais propensão dos 
homens desenvolverem a doença (ASCHERIO et al, 2003); mulheres na pósmenopausa sem receber terapia de reposição hormonal ainda não teve comprovação se teriam risco aumentado em relação àquelas que o fazem (WANG et al, 2014).

\subsection{Etiologia da DP}

A DP propriamente dita está relacionada à forma idiopática da doença, que apesar de não ter causa definida, se apresenta sob um caráter multifatorial (TANNER et al, 2011). Além disso, dados epidemiológicos também sugerem uma possível associação entre exposições ambientais e aumento do risco da DP. Algumas exposições que têm sido associados a um maior risco incluem exposição de vida para água de poço, traumatismo craniano, dieta, vida rural, e infecções. Existe uma literatura crescente que liga exposições ambientais tóxicas, como à rotenona e ao paraquat, ao risco da DP (TANNER et al, 2011), inclusive esses agentes podem ser utilizados em laboratório para gerar modelos animais de parkinsonismo e indicam papel da disfunção mitocondrial e aumento do stress oxidativo na etiologia da DP (TANNER et al, 2011).

A contribuição da genética molecular tem sido determinante, porque permite abrir novas vias de exploração de proteínas, vias metabólicas e outros processos celulares envolvidos. Grandes estudos mundiais do genoma também mostraram o risco genético moderado para a DP esporádica que inclui polimorfismos dos genes da alfa-sinucleína, LRRK2 e GBA (LEES, HARDY, REVESZ, 2009). Formas monogênicas representam cerca de $30 \%$ da forma familiar e $3 \%$ a $5 \%$ dos casos esporádicos, mas vários loci de susceptibilidade foram identificados (SHULMAN, De JAGER, FEANY, 2011). As formas hereditárias de DP - denominadas de "PARK" e numeradas sequencialmente - representam minoria dos casos da doença. Formas hereditárias monogênicas da DP de transmissão autossômica dominante (AD) são PARK1, 3, 4, 5 e 8, enquanto PARK6 e 7 são autossômicas recessivas (AR); PARK2 é essencialmente AR, mas poderá haver casos de transmissão AD. Considera-se 
DP de início precoce se sintomas surgem até aos 40 anos de idade e juvenil se até aos 21 anos (SCHAPIRA, TOLOSA, 2010).

\subsection{Fisiopatologia da DP}

Sintomas como a rigidez, bradicinesia e tremor em repouso são as principais manifestações motoras da DP, as quais, classicamente, são associadas a alterações funcionais dos núcleos da base (NB). Em um indivíduo normal, os NB estão funcionalmente interpostos entre o córtex e o tálamo. As aferências do córtex sensório-motor são recebidas pelos NB através do estriado (caudado e putâmen). Esta informação é processada e transmitida ao globo pálido segmento interno (GPi) e SN pars reticular (SNr) que são os núcleos de saída dos NB. Esta transmissão aos núcleos de saída pode ocorrer por duas vias: diretamente do estriado aos núcleos de saída (via direta); ou via globo pálido externo (GPe) e núcleos subtalâmicos (via indireta). O GPi e a SNr projetam em direção a núcleos de distribuição talâmicos (núcleo ventral anterior e ventral lateral) os quais projetam para áreas corticais. A ativação da via direta provoca uma desinibição dos neurônios da região alvo dos NB, enquanto a ativação da via indireta leva a uma inibição destes neurônios (OBESO et al, 2002).

A DP é resultado das modificações de NTs em diferentes níveis cerebrais e que decorrem da falha dos mecanismos compensatórios para estabilizar os NB (OBESO et al, 2002). Seus mecanismos fisiopatológicos da DP mostram que o estriado além de receber projeções glutamatérgicas excitatórias corticais também recebe projeções dopaminérgicas de neurônios localizados na SN pars compacta (SNc). Estes neurônios dopaminérgicos exercem efeito excitatório, através da ativação de receptores da dopamina (DA) do tipo 1 (receptores D1), sobre os neurônios estriatais que dão origem à via direta; e um efeito inibitório, por meio da ativação de receptores do tipo 2 (receptores D2), que dão origem à via indireta. $A$ perda de neurônios dopaminérgicos na SNc, inclusões intraneuronais de corpos de Lewy $(\mathrm{CL})$ e severa deficiência de DA no caudado, putamen, globo pálido, núcleo acumbens e núcleo subtalâmico são característicos da DP (OBESO et al, 2002; BEZARD, GROSS, BROTCHIE, 2003). 
Ressalta-se que na via estriado-GPe além da ação do GABA como NT, também ocorre a ação da encefalina que é derivada a pré-proencefalina; cujo nível de mRNA está elevado antes do aparecimento dos sintomas, tendo sido proposto como um possível mecanismo compensatório para reduzir a hiperatividade gabaérgica para o GPe (BEZARD, GROSS, BROTCHIE, 2003).

Em decorrência da perda de neurônios dopaminérgicos na SN há uma redução de entrada de DA no estriado. A degeneração dos neurônios dopaminérgicos na SNc induz a uma cascata de alterações que afeta todos componentes do circuito dos NB. Os núcleos de saída (GPi e SNr) tornam-se hiperativos. Esta hiperatividade deve-se ao aumento da estimulação glutamatérgica que os núcleos de saída recebem dos núcleos subtalâmicos. A disfunção do circuito dos NB, observa-se perda de ação inibitória do segmento lateral do globo pálido sobre o núcleo subtalâmico, bem como existe uma ação hiperexcitatória do núcleo subtalâmico sobre o segmento medial do globo pálido, assim, ocorre um aumento da atividade gabaérgica dos núcleos de saída, o que provoca uma inibição do tálamo motor e possivelmente uma redução na sinalização talamocortical, cujo resultado final será uma menor ação excitatória do tálamo sobre o córtex motor, determinando a síndrome rígido-acinética. A apresentação desse quadro é desigual em sua distribuição, afetando primeiramente os músculos proximais, especialmente ombros e pescoço, progredindo para os músculos da face, membros superiores e inferiores.

\subsection{Neuropatologia da DP}

Anatomopatologicamente a característica mais conhecida da Doença de Parkinson é a degeneração e morte dos neurônios pigmentados dopaminérgicos da pars compacta da substância negra (SNc) - descrito por Édouard Brissaud em 1895. Dezessete anos depois Lewy publicou a presença de inclusões eosinofílicas intracelulares em doentes com DP, hoje conhecidas como Corpos de Lewy (CL) (GOEDERT et al, 2013).

Embora os CL tenham sido identificados há mais de um século, a sua importância para o processo de patogenicidade da PD permanece desconhecida (GOEDERT et al, 2013). Eles são agregados filamentosos citoplasmáticos 
insolúveis, contendo a-sinucleína, encontrados nas regiões afetadas. Muitas evidências sugerem que na DP as lesões neuropatológicas com a-sinucleína podem, de forma progressiva, se espalhar e auto-propagar entre regiões cerebrais interligados por mecanismo de transmissão intercelular. Apoiando esse conceito, estudos anatomopatológicos mostraram acúmulo patológico de a-sinucleína em diferentes regiões do cérebro com padrão de progressão caudorostral (BRAAK at al, 2003; DICKSON et al, 2009; ULUSOY et al, 2013)

O diagnóstico clínico é baseado rotineiramente nos sintomas motores, e nesse ponto a doença já está em franca ascensão (HALLIDAY, LEES, STERN, 2011), mas de fato, a alteração nigral clássica da DP já está acompanhada de uma fisiopatologia dita extranigral, caracterizada por acometimentos nos núcleos dorsal motor dos nervos glossofaríngeo e vago, formação reticular, região da rafe, complexos coeruleous-subcoeruleous, núcleo magnocelular do bulbo, e muitos subnúcleos da amígdala e tálamo (BRAAK et al, 2003; HALLIDAY, LEES, STERN, 2011).

Em 2003 foi publicado o estudo "Staging of Brain Pathology Related to Sporadic Parkinson" que representou grande importância no estadiamento da doença a partir de seu comprometimento neurodegenerativo (BRAAK et al, 2003) e serviu de marco para melhor compreensão dos sintomas da fase pré-motora, inclusive aqueles que podem preceder em décadas os sintomas motores, como distúrbio olfativo e transtornos do sono e do humor (CHAUDHURI, HEALY, SCHAPIRA, 2006; KRANICK, DUDA, 2008).

A fase inicial no estagiamento de Braak e colaboladores se baseou na presença dos $\mathrm{CL}$, neuríticos e/ou globulares, em pequeno número na porção caudal do tronco cerebral. A evolução da doença se estabeleceu pelo aumento do número e aparecimento em novas estruturas desses corpos, como também da degeneração neuronal. Foi concluído que a DP tem seu início na parte caudal do tronco cerebral, particularmente no núcleo motor dorsal do vago (NMDV) e no núcleo olfativo anterior, evoluindo em seis estágios, até comprometer áreas de associação e regiões corticais, conforme observa-se na figura 1 (BRAAK et al, 2003). 

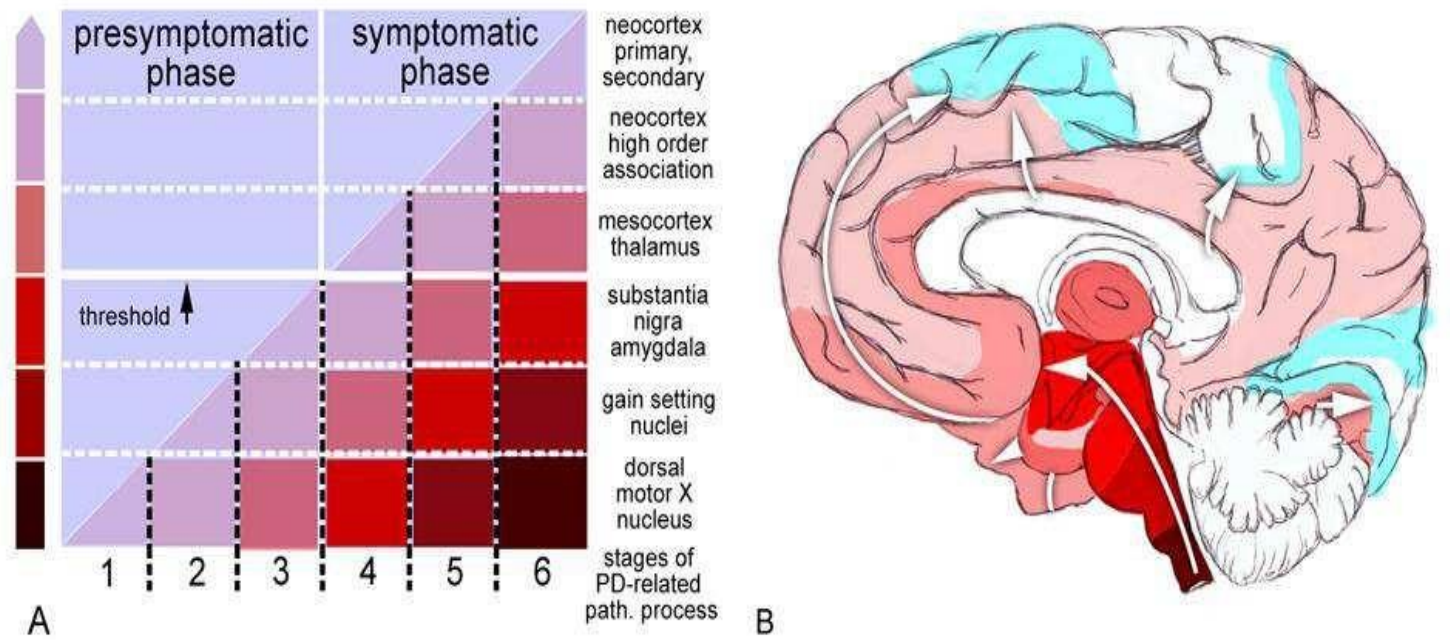

Figura 1 - Estágios relacionados ao desenvolvimento da DP: regiões atingidas pelas lesões com $\mathrm{CL}$ e neuritos de Lewy, que se iniciam na medula oblonga (núcleo dorsal do nervo vago - IX e X) e bulbo olfatório seguindo pelo tronco encefálico até o córtex cerebral (direção das flechas). Fonte: Cell Tissue Res. 2004 Oct;318(1):121-34.

\section{- Estágio 1}

As estruturas inicialmente envolvidas neste estágio são o NMDV, a formação reticular bulbar e o núcleo olfatório anterior, evidenciadas pela presença dos primeiros corpos neuríticos de Lewy (BRAAK et al, 2003). O NMDV tem a acetilcolina como neurotransmissor (NT), sua perda neuronal se expressa por constipação intestinal sugerindo que tal sintoma possa anteceder, em muitos anos, à fase motora (SIDDIQUI et al, 2002). O comprometimento da formação reticular bulbar, cujos NTs são a noradrenalina e a acetilcolina, leva aos distúrbios do sono, tais como, insônia inicial, fragmentação do sono, despertar precoce, sonhos vívidos, pesadelos, movimentos periódicos dos membros (MPM) e o transtorno comportamental do SREM (TCSREM) (FRIEDMAN, MILLMAN, 2008), distúrbios que podem preceder em anos os sintomas motores. As alterações no núcleo olfativo anterior, que é mediado pela noradrenalina, leva à hiposmia/anosmia. A prevalência da disfunção olfativa na DP varia de 70 a $90 \%$, e é importante marcador da fase pré-motora (KRANICK, DUDA, 2008).

\section{- Estágio 2}


A ponte é acometida, especialmente os núcleos da rafe, formação reticular e locus coeruleus (BRAAK et al, 2003). Através do sistema límbico, as células serotoninérgicas dos núcleos da rafe interferem na regulação do humor e do afeto, assim a deficiência da serotonina pode levar a sintomas depressivos e de ansiedade (WOLTERS, BRAAK, 2006). A formação reticular, situada na ponte e mesencéfalo, tem a acetilcolina como um dos NTs e está relacionada ao ciclo de sono-vigília. Sabe-se que 80 a $90 \%$ dos pacientes com DP apresenta distúrbios do sono (FRIEDMAN, MILLMAN, 2008), e entre eles está o TCSREM relacionado aos neurônios colinérgicos que pode preceder as manifestações motoras em décadas mais de $52 \%$ dos pacientes (OLSON, BOEVE, SILBER, 2000). O locus coeruleus noradrenérgico faz parte do sistema envolvido na inibição da dor. Na DP, a dor constitui uma das manifestações não-motoras, podendo ocorrer em $40 \%$ a $75 \%$ dos pacientes (CHUDLER, DONG, 1995).

\section{- Estágio 3}

Nesse estágio começam a ser encontrados os CL na pars compacta da SN mesencefálica e nos núcleos magnocelulares basais do prosencéfalo (septal medial, intersticial da banda diagonal e o basal de Meynert). $\mathrm{Na} S \mathrm{SN}$ os melanócitos produzem dopamina que, transportada pela via nigro-estriatal, é armazenada no núcleo estriado, em especial no putâmen. Do seu comprometimento resultam os sintomas motores clássicos (tremor, rigidez e bradicinesia), que no ocorrerão tardiamente, após $60 \%$ de perda celular. Os núcleos magnocelulares basais do prosencéfalo - mediados pela acetilcolina - estão correlacionados com a cognição e o ciclo sono-vigília, assim, distúrbios como hipomnésia, déficits na atenção e concentração, podem anteceder, acompanhar ou suceder aos sintomas motores clássicos (WOLTERS, BRAAK, 2006).

\section{- Estágio 4}

É iniciado acometimento dos neurônios de projeção do núcleo pedunculopontino, porção basal do telencéfalo, núcleos tuberomamilar hipotalâmicos, da amígdala e do tálamo. A degradação dos núcleos olfatórios é mais intensa neste estágio, mas a maior característica é a degradação da porção 
anteromedial do mesocórtex temporal (BRAAK et al, 2003). Devido às alterações degenerativas nas conexões do mesocórtex temporal com o neocórtex pré-frontal (por via da amígdala e da formação hipocampal), ocorrem disfunções mnemônicas e executivas, perda da auto-iniciativa e apatia. O comprometimento dos núcleos mesencefálicos da rafe agrava as manifestações citadas nos estágios 2 e 3, principalmente a depressão e os distúrbios do sono (WOLTERS, BRAAK, 2006).

\section{- Estágio 5}

A partir deste estágio, as alterações neuropatológicas progridem do mesocórtex temporal ao neocórtex (BRAAK et al, 2003) como demonstra a figura 2. Assim, são acometidas áreas pré-frontais, áreas de associação sensitivas, campos insulares granular e agranular, e, giro do cíngulo anterior. O comprometimento do neocórtex acentua as disfunções cognitivas (desatenção e hipomnésia), que acrescidas de agnosia e apraxia, podendo configurar início de processo demencial, conforme verifica-se na figura 2 (WOLTERS, BRAAK, 2006).
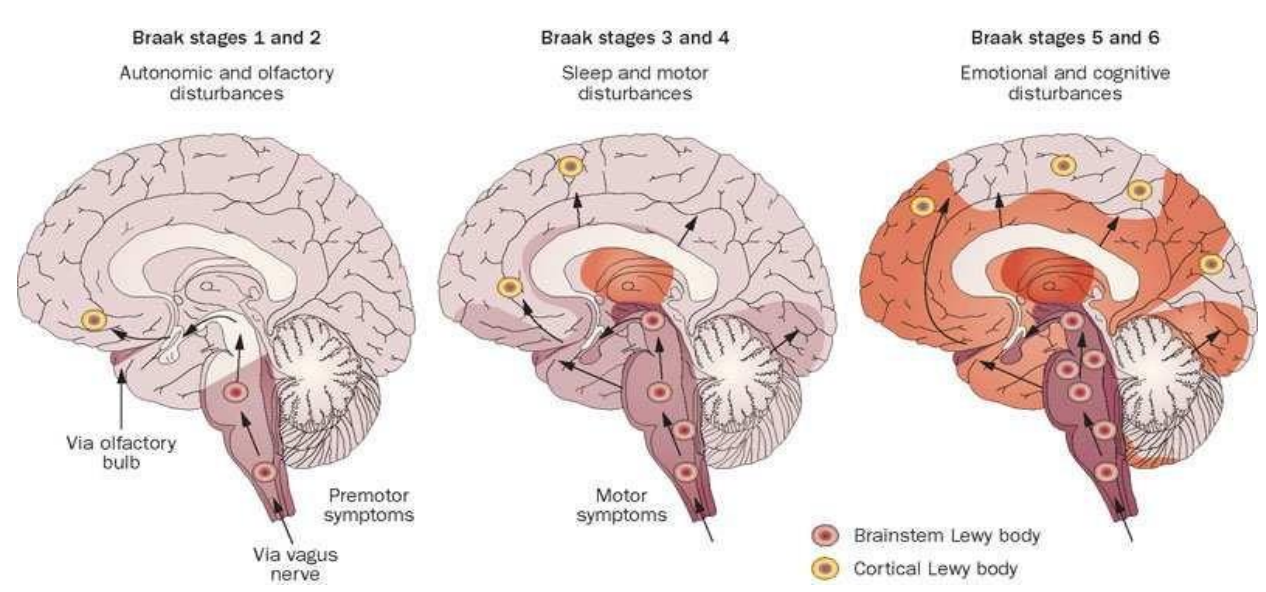

Figura 2 - The Braak stages of PD. Fonte: Doty RL (2012) Nature Reviews Neurology 8, 329-339.

\section{- Estágio 6}

Nessa fase ocorre um prejuízo em quase todo o neocórtex, áreas pré-motoras e área motora primária 9,13, além das áreas sensoriais primária e de associação, chega à primeira circunvolução temporal e frequentemente alcança a área primária auditiva - o giro transverso de Heschl's. Os danos em áreas límbicas importantes 
(amígdala, formação hipocampal, mesocórtex temporal anteromedial) juntamente com lesões em áreas extensas do neocórtex parecem justificar o declínio das faculdades intelectuais observadas principalmente nas fases mais adiantadas da DP (BRAAK et al, 2003).

Além das manifestações correspondentes aos estágios anteriores, agravamse as dificuldades motoras, como rigidez, bradicinesia e instabilidade postural, podendo levar à incapacidade de locomoção. Costuma ocorrer, ainda, exacerbação das alucinações e dos delírios, assim como, agravamento das alterações cognitivas e comportamentais, podendo evoluir para demência (CUMMINGS, 2004).

\subsection{Correlações Clínico-Patológica dos Subtipos Motores}

Além do estagiamento de Braak e equipe, também existem as correlações clínico-patológica onde os subtipos motores e de idade de início podem ser correlacionados com achados patológicos específicos (SELIKHOVA et al, 2009, WICHMANN et al, 2011). No estudo de Selikhova e colaboradores (2009) houve a classificação em grupos de início precoce, de evolução rápida, de forma predominante rígida e da forma onde predomina o tremor, em 242 casos verificados em autópsia de portadores da DP. A progressão foi mais distinta entre o início precoce e outros grupos, onde aquele teve maior sobrevida e mais tempo sem complicações como quedas, demência e alucinações, porém teve mais precocemente a presença de discinesias. Patologicamente, a forma rígida (FR) teve maior quantidade de $\mathrm{CL}$, particularmente nas regiões frontais e transentorrinal, bem como uma maior frequência de emaranhados neurofibrilares e depósitos amilóide, que a forma tremulante (FT). Rajput e seu grupo de pesquisadores (2009) examinaram os níveis de dopamina post mortem em grupos de doentes com fenótipos da DP divididos em FT, FR e forma mista, e, encontraram níveis de dopamina significativamente mais elevados no globo pálido e estriado entre aqueles com tremor predominate; favorecendo as hipóteses acerca das diferenças biológicas entre os subtipos motores tradicionais da PD. 


\subsection{Manifestações clínicas da Doença de Parkinson}

A DP tem um padrão de manifestações motoras que promovem 0 diagnóstico baseado na identificação nas características clínicas, tais como bradicinesia, tremor, rigidez e instabilidade postural (LANGSTON, 2006). No entanto, estudos neuropatológicos revelaram que a perda neuronal ocorre além do sistema dopaminérgico, e consequentemente, justificam os sintomas não-motores (BRAAK et al, 2004, WOLTERS, 2008). Nas últimas décadas, estudos clínicos, epidemiológicos e histopatológicos forneceram mais evidências a favor da existência da fase dos sintomas não motores (SNM), a fase pré-motora, na qual os distúrbios do sono tendem a serem mais valorizados (TOLOSA, 2007).

Muito embora seja identificada como um distúrbio do movimento, a DP está associada a uma gama de sintomas não-motores, inclusive muitos citados no "Ensaio sobre a paralisia agitante", artigo de James Parkinson, 1817. Nele estão descritos transtornos do sono (TS), fadiga (cansaço extenuante), constipação, disartria, disfonia, disfagia, sialorréia, e incontinência urinária. Muitas destas manifestações podem preceder em anos o diagnóstico da DP ou ocorrer nos estágios iniciais (ADLER, 2005, CHAUDHURI, NAIDU, 2008).

Os substratos neuroanatômicos e neuroquímicos para o complexo dos SNM na DP permaneceram desconhecidos até a descoberta feita por Braak e colaboradores, 2013, que introduziu o conceito de um processo patológico de seis estágios colocando estruturas extranigrais no centro de interesse como o núcleo motor dorsal do vago, bulbo olfatório, os núcleos seratoninérgicos da rafe e o complexo colinérgico do tronco cerebral (BRAAK et al, 2003), esse estagiamento contribui para o entendimento dos SNM, em especial o déficit olfativo, depressão e TCSREM que podem preceder a doença, e caracterizam a fase pré-motora da DP (WOLTERS, 2008).

Apesar da atenção dada aos sintomas motores, vários estudos têm demonstrado que os SNM da DP têm ainda maior significado quando avaliados nas medidas relacionadas à qualidade de vida, às taxas de institucionalização e nos fatores econômicos das políticas de saúde, até porque é possível correlacionar os SNM com o avançar da idade e a gravidade da doença, (FINDLEY et al, 2002). 
Mesmo com essa importância, há pouco reconhecimento desses sintomas na prática clínica, como demonstrado em estudo que observou que alterações de sono não eram identificadas pelos neurologistas em taxa superior a $40 \%$ durantes as consultas de rotina (SHULMAN et al, 2002).

Os efeitos colaterais dos medicamentos que tratam os sintomas motores, podem induzir ou agravar alguns dos SNM como hipotensão ortostática, alucinações, sonolência excessiva e insônia e assim interferir de forma significativa na qualidade de vida destes indivíduos (POEWE, 2008, YORITAKA et al, 2014). O estudo de Relja e Mileti, 2010, investigou SNM em 56 pacientes com DP e mostrou que as mais frequentes foram depressão, $43,3 \%$, seguido por constipação $35,3 \%$, e, dor inexplicada em $29,3 \%$, principalmente na região do ombro. O achado do sintoma álgico foi verificado como um sinal prodrômico, e, também como uma condição comórbida na fase mais avançada da doença. A seguir são apresentados alguns dos SM e SNM da DP:

\subsubsection{Sintomas Motores (SM)}

\section{Tremor de repouso}

O tremor característico da DP é um tremor distal, inicialmente unilateral, observado em repouso com freqüência de 4 a $6 \mathrm{~Hz}$ que torna-se mais evidente quando a mão está em repouso durante situações de estresse. $O$ tremor consiste em contrações rítmicas de um determinado grupo muscular alternadas com a do seus antagonistas, como na supinação-pronação no tremor de "contar dinheiro" ou "enrolar pílulas" (JANKOVIC, 2008), como nota-se na figura 3. O tremor de repouso em pacientes com DP pode também envolver lábios, queixo, mandíbula e pés (STAMEY, JANKOVIC, 2007).

\section{Rigidez muscular}

A rigidez muscular é outro sintoma típico da doença, verificando-se um acometimento, principalmente, da musculatura axial flexora e pode levar a alterações típicas da postura (JANKOVIC, 2008). Essa rigidez é caracterizada pelo aumento da resistência, denominada plástica ou "cérea", geralmente acompanhado pelo fenômeno da "roda denteada", principalmente quando associada a um tremor 
subjacente, presente em toda a a amplitude de movimento passivo de um membro (flexão, extensão ou rotação sobre uma articulação). Pode ocorrer na região proximal, como no pescoço, ombros e quadris, como distalmente em pulsos e tornozelos. Essa alteração no tônus promove a diminuição da amplitude e pode estar associada à dor, sendo o ombro doloroso uma das manifestações iniciais mais freqüentes da PD, apesar de ser geralmente diagnosticada como artrite, bursite ou lesão no manguito rotador (RILEY et al, 1989, STAMEY, JANKOVIC, 2007).

\section{Hipocinesia / Bradicinesia}

A hipocinesia é a redução/limitação dos movimentos, principalmente os automáticos, e pode ser considerada como a dificuldade encontrada por indivíduos com DP na troca de movimentos, ou seja, iniciar um movimento e interrompê-lo a fim de começar um novo (JANKOVIC, 2008). Pode ser observada na diminuição do balançar dos braços durante a deambulação, dificuldade de manter um movimento repetitivo como abrir e fechar as mãos ocorrendo tendência do movimento reduzir e esgotar (GOBBI et al, 2006). A perda da expressão facial (hipomimia) e a diminuição do piscamento também são sinais comuns da DP (JANKOVIC, 2008).

Por sua vez o freezing (congelamento) caracteriza-se pela acinesia súbita ou numa hesitação no início da marcha com frenação súbita dos membros inferiores, e é um dos mais incapacitantes sintomas da DP, mas embora seja uma característica da doença, não ocorre obrigatoriamente (MACHT et al, 2007). É associado com consequências negativas sociais e clínicas para os pacientes. Em particular, é causa comum de quedas (MACHT et al, 2007). Fatores de risco para o desenvolvimento de congelamento incluem a presença de rigidez, bradicinesia, instabilidade postural e maior duração de doença, ou seja sintomas do subtipo motor rígido (JANKOVIC, 2008). Em geral acomete as pernas durante uma caminhada, mas braços e pálpebras também pode estar envolvidos. Isso pode incluir a hesitação do início da marcha ou uma súbita incapacidade para mover os pés durante situações específicas, que em geral dura cerca de 10 segundos, exemplo: quando o paciente se depara com um obstáculo real, como uma pequena elevação do solo, ou apenas visual, como uma faixa pintada no chão. Também de atravessar uma passagem 
estreita ou uma rua movimentada. Outras vezes, uma situação de tensão emocional pode desencadear o fenômeno (STAMEY, JANKOVIC, 2007).

A bradicinesia refere-se à lentidão de movimentos, que é provocada pela grande dificuldade em gerar pulsos neuromotores que mantenham o andamento do movimento desejado durante a ação, ou seja, a sequência da ação motora. Abrange dificuldades com o planejamento de iniciar e executar o movimento, além da realização de tarefas sequenciais e simultâneas (GOBBI et al, 2006). A manifestação inicial da DP caracteriza-se muitas vezes por lentidão na realização de atividades de vida diária, pela vagarosidade dos movimentos e aumento do tempo para início da reação, Isso pode ser observado nas dificuldades em realizar tarefas que exigem com controle motor fino, como abotoar e escovar dentes (BERARDELLI et al, 2001). Outras manifestações de bradicinesia incluem a diminuição da gesticulação espontânea, perda da deglutição automática com aumento da saliva e "babação", disartria com voz hipofonética monótona e micrografia progressiva (JANKOVIC, 2008).

\section{Instabilidade postural}

A instabilidade postural é outra manifestação observada nesses pacientes, porém mais visível nas fases mais adiantadas, em especial na forma rígida (FR); ocorre quando há uma perda dos reflexos da readaptação postural, evidenciando-se em mudanças bruscas de direção durante a marcha, e, posteriormente, podendo agravar-se determinando quedas freqüentes. A postura geral do paciente modificase: existe predominância dos músculos flexores, de modo que a cabeça permanece fletida sobre o tronco, este sobre o abdômen, e os membros antebraços semifletidos (JANKOVIC, 2008).

Há dificuldade na percepção da própria postura e juntamente com o congelamento de marcha, esse desequilíbrio postural é o maior causador de quedas, e assim contribui significativamente para o risco de fraturas, especialmente fêmur e quadril, com risco de mortes ou sequelas motoras (WILLIAMS, WATT, LEES, 2006). Vários outros fatores influenciam também a ocorrência de instabilidade postural, estes incluem os SNM como hipotensão ortostática, alterações sensoriais e 
a integridade dos sistemas visual, vestibular e proprioceptivo da doença e relacionadas à idade (NEVITT, 1989).

Manifestações clínicas da doença de Parkinson

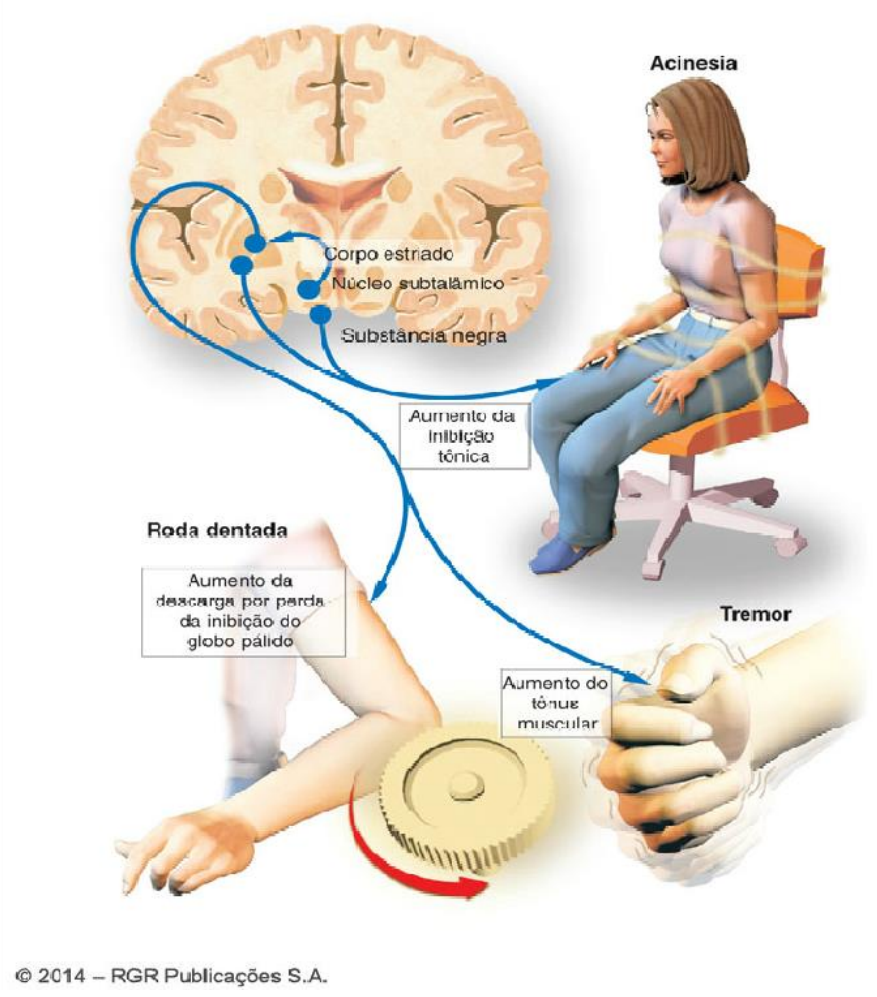

Figura 3. Sinais na apresentação dos SM da DP. Extraído de www.ecsaweb.com.

\subsubsection{Sintomas Não Motores (SNM)}

Alguns dos SNM precedem a fase motora da DP, porém, atualmente, somente o déficit olfativo é considerado potencial marcador pré-clínico para doença (WOLTERS, 2008). A dor tem causas secundárias além da DP, tais como problemas músculo-esqueléticos, espondilorradiculopatias, além daquelas associadas à acatisia, espasmos distônicos, e até pela rigidez muscular que podem ocorrer na DP. Os pacientes também podem apresentar dor primária de origem central, descritas como sensações dolorosas inexplicáveis e bizarras, predominando no lado mais afetado no período off (CHUDLER, DONG, 1995).

Além disso, outros SNM são prevalentes na doença, como: 
- Neuropsiquiátricos: depressão, fadiga, apatia, ansiedade, déficit de atenção, alucinações, demência, comportamento obsessivo, confusão, ataques de pânico;

- Autonômicos: distúrbios vesicais, sudorese, hipotensão ortostática, disfunção sexual;

- Gastrointestinais: constipação, salivação, perda do paladar, disfagia;

- Sensoriais - distúrbios olfativos e do paladar, alterações visuais, dor .

- Transtornos do sono (TS) - Síndrome das Pernas Inquietas (SPI) e Movimentos Periódicos dos Membros (MPM), Transtorno Comportamental do Sono REM (TCSREM), distúrbios do movimento relacionados com o Sono Não REM, Sonolência Excessiva Diurna (SED), fragmentação do sono;

- Outros sintomas: diplopia, seborréia, perda de peso.

\subsection{O Sono Normal}

O sono é uma condição fisiológica de atividade elétrica cerebral, natural e periódica, caracterizada por modificação do estado de consciência, redução da sensibilidade aos estímulos ambientais, acompanhados por características motoras e posturais próprias, além de alterações autonômicas (MIGNOT, 2008). Foram identificados padrões específicos de Eletroencefalograma (EEG) associados ao sono, como o sono dos movimentos oculares rápidos (Rapid Eye Movement) chamado de Sono REM (20-25\%) e aqueles sem movimentos oculares rápidos (nonrapid eye movement - NREM). O sono NREM se divide ainda em três estágios: N1 (<5\%), N2 (40-45\%) e N3 (15-20\%). A fase N3 do SNREM também é chamada de "sono de ondas lentas", quando há lentificação da atividade elétrica cerebral, ocorrendo predomínio da atividade parassimpática, com a presença do descenso pressórico noturno e diminuição fisiológica do metabolismo cerebral e sistêmico (GOMES, QUINHONES, ENGELHARDT, 2010). A função do sono ainda não totalmente elucidada, porém, dentre as hipóteses aventadas a que apresenta maior evidência é que durante o sono ocorreria a promoção e facilitação para conservar a energia e atuaria na plasticidade cerebral através do incremento da sinaptogênese, 
contribuindo para o aprendizado e consolidação da memória (MIGNOT, 2008;

GOMES, QUINHONES, ENGELHARDT, 2010).

\subsection{Transtornos do Sono na DP}

James Parkinson descreveu em 1817 alguns TS da doença, mas também chamou atenção para a SED na DP como no fragmento do texto: "sonolência constante com leve delírio e outras marcas de cansaço extremo". Os TS e a SED atualmente tem indicativos de surgirem a partir de combinações de alterações neuroquímicas e neurodegenerativas em centros reguladores centrais do sono, tais como o prosencéfalo, o tálamo e neurônios dopaminérgicos mesencefálicos (BRAAK, 2003). Rye e Jankovic (2002) apontaram que os TS e a sonolência diurna são frequentemente secundários a uma hipoatividade da resposta à estimulação dopaminérgica, e alteração na transmissão dopaminérgica nos órgãos alvo.

A percepção de distúrbio no sono noturno e sonolência diurna, são queixas frequentes em pacientes com DP, aventando-se que 60 a $90 \%$ dos portadores tem queixas relacionadas ao sono (CHAUDHURI, HEALY, SCHAPIRA, 2006). Das manifestações que ocorrem com maior frequência temos a insônia, sono fragmentado, sonolência excessiva diurna e sleep attacks (ataques de sono), Transtorno Comportamental do Sono REM (TCSREM) e outras parassonias, síndrome da apnéia obstrutiva do sono (SAOS), síndrome das pernas inquietas (SPI) e movimentos periódicos dos membros (MPMs). Os doentes ainda podem ter alguns destes distúrbios precipitados ou piorados pelas medicações, assim como a falta destas podem causar desconforto noturno por dificuldade ou incapacidade de se mexer no leito (YORITABA, 2014). A SPI, assim como o TCSREM podem preceder ou ocorrer precocemente na DP, afetando mais o sexo masculino (ZOCCOLELLA et al, 2010).

A polissonografia (PSG) é o método mais objetivo e considerado como padrão ouro para mensurar parâmetros da arquitetura do sono e seus eventos fisiopatológicos. Na DP alguns estudos têm indicado que a latência para iniciar o sono, a frequência de despertares, e o número total de horas dormidas aumentam com a progressão da doença (GJERSTAD et al, 2007). Além disso, uma significante 
diminuição no tempo total de sono e na duração do sono de ondas lentas (N3) em relação ao sono mais leve (N1 e N2) nos indivíduos com DP, também se evidencia nos estudos de sono com PSG (ZOCCOLELLA et al, 2011). Tais fatores apontam para a importância do sistema dopaminérgico na manutenção do sono normal, evidenciando, portanto, que os distúrbios do sono - que são conhecidos de longa data - fazem parte do espectro da patologia (LEES, BLACKBURN, CAMPBELL, 1988), não obstante, ainda são pouco investigados e contribuem como importante fator preditivo de má qualidade de vida (SCARAVILLI, 2003).

Desse modo, os principais distúrbios do sono associados à DP são:

- TCSREM: movimentos corporais apresentados durante fase dos sonhos, levando a ações e verbalizações representando os conteúdos dos sonhos ou pesadelos. Comumente tais movimentos são associados a sonhos de conteúdo violento.

- SPI / MPMs: enquanto a SPI envolve sensações desconfortáveis e a necessidade de movimentar as pernas, especialmente ao deitar no início da noite, antes do adormecer e dificultando o processo do início do sono, os Movimentos Periódicos de Membros ocorrem durante o sono e pode determinar superficialização e microdespertares decorrentes dessa movimentação anormal.

- Sono fragmentado: despertares do sono noturno podem ter várias razões, desde o avanço dos sintomas motores (tremor, rigidez e espasmos), efeitos colaterais das medicações, dores nos membros inferiores, noctúria, a quadro depressivo. As perda de habilidades automáticas na evolução da doença, como mudança de decúbito em geral pela rigidez muscular, principalmente do tronco também causam fragmentação do sono.

- Sonhos e pesadelos vívidos: ocorrem com frequência e podem ser aumentados pelas drogas antiparkinsonianas. Menos comumente esses sonhos ou pesadelos podem transitar para o período de vigília e serem confundidos com alucinações.

- SAOS: o fluxo aéreo reduzido ou interrompido durante a apneia, ocorrendo de forma intermitente durante o sono pode levar à privação crônica, 
fragmentação de sono e até hipóxia, com consequente fadiga e sonolência diurna, além da repercussão cognitiva.

\subsection{O Efeito do Sono da DP}

O sono tipicamente tem um efeito em melhorar os sintomas motores da DP. O padrão mais comum é o benefício sobre o tremor, assim como a bradicinesia/hipocinesia e rigidez associada às funções não motoras dependentes de dopamina nas primeiras horas da manhã (STRUCK, RODNITZKY, DOBSON, 1990). Outro efeito salutar do sono, também se mostram através dos SM e dos SNM da doença ao longo do dia, havendo evidências de que a falta de qualidade do sono está associada com piora das funções executivas, além da piora dos sintomas motores, em pacientes, aparentemente, sem demência (STAVITSKY et al, 2012).

\subsection{Sonolência Excessiva Diurna}

A SED é definida como a incapacidade de permanecer acordado e alerta durante a maior parte do dia, resultando em períodos de necessidade irreprimível para sono com lapsos não intencionais de sonolência ou de sono. A SED pode variar em gravidade e é mais provável ocorrer em situações sedentárias, entediantes ou em situações cotidianas rotineiras, como por exemplo, assistindo televisão, lendo ou dirigindo, e assim interferir com a qualidade da vida familiar, profissional e social (ARNULF, 2009). Alguns indivíduos estão conscientes do aumento da sonolência antes de adormecer, enquanto outros podem adormecer sem nenhum sintoma prodrômico (ataques de sono).

\subsubsection{Sonolência Excessiva Diurna na DP}

$\mathrm{Na}$ DP a SED ocorre em cerca de $50 \%$ dos acometidos e tem impacto relevante para a qualidade de vida e pode chegar a ser mais incapacitante do que os sintomas motores (KINE et al, 2011). A sonolência também pode preceder os 
sintomas parkinsonianos clássicos, como visto em um estudo asiático, onde a incidência de DP foi três vezes maior em homens com SED comparado com aqueles sem SED, persistindo a associação entre o surgimento da SED e o risco para o desenvolvimento da DP após análise de outros fatores (ABBOT et al, 2005).

A hipótese mais recentemente aceita sobre os TS, que ocorrem em cerca de 90\% dos portadores da DP (HOGLUND et al, 2015), é que a neurodegeneração afeta as áreas do cérebro envolvidas no controle de sono e de vigília, compostas pelos núcleos supraquiasmáticos do hipotálamo e circuitos mesocorticolimbicas incluindo a área ventral tegmental, núcleo coeruleus, e o hipotálamo (HOGLUND et al, 2015). Os efeitos no tronco cerebral influenciariam na ocorrência do TCSREM, MPM e SPI levando a SED inicialmente, mas também deve ser considerado os efeitos colaterais do tratamento, ou ainda que os TS possam estar sendo piorado pelas ações adversas das medicações (KINE et al, 2011; HOGLUND et al, 2015). Recentemente, porém, nota-se um incremento de evidências que indicam que a SED seria mais uma manifestação da progressão da doença assim como relatou James Parkinson em 1817, além de evidências com achados anatomopatológicos da associação com a forma rígida e maior chance de evolução para demência (HOGLUND et al, 2015).

Yoritaka e colaboradores (2014) verificaram ocorrência de ataques de sono em $0.4 \%$ de uma população de 1.453 portadores da DP que foi estudada desde os primeiros dois anos da doença, porém, essa porcentagem aumentava gradativamente ao longo do tempo, até atingir $10.5 \%$ ao fim de 12 anos de seguimento. Esses ataques de sono eram muito frequentemente associados a agonistas dopaminérgicos (pramipexol e ropinirol), sendo que o sexo masculino era mais propenso, sem correlação com a dose.

A ligação entre a sonolência excessiva diurna e os sintomas não motores avaliados pela UPDRS também já foi estudada sendo observado que tal associação foi inversamente proporcional à idade (CHEN et al, 2013). No entanto, interações entre a DP e o sono são complexas porque muitas das manifestações relacionadas com o sono não são específicos para DP (LANG et al, 2001). 


\subsection{Fadiga}

A fadiga pode ser definida como falta de energia mental e/ ou física, acompanhada por um desejo de reduzir ou limitar os níveis de atividade, mesmo na ausência de incapacidade para tal. Ocorre também uma perda de vigor mental, porém sem uma tendência real para adormecer. Embora frequentemente reconhecida como um sinal ou sintoma de uma doença, ou efeito secundário de tratamento, a fadiga é uma experiência subjetiva, principalmente pela ausência de um marcador biológico (FRIEDMAN et al, 2010). De acordo com o Glossário de Termos Técnicos do Manual Diagnóstico e Estatístico de Transtornos Mentais (DSM 5), fadiga significa um estado de exaustão, cansaço, letargia, abatimento, languidez, lassidão e apatia, geralmente associado a enfraquecimento ou sensação de esgotamento dos recursos físicos e/ou mentais. Pode ser primária e para tal consideração deve ser afastada a possibilidade de doenças orgânicas tais como hipotiroidismo, insuficiência hepática ou renal, anemia, distúrbios do sono, viroses, 1 neoplasia maligna, entre outros (KITAl et al, 2012). É um dos sintomas mais relatados em consultas de atenção primária, como mostrou estudo do departamento de saúde da família da Universidade de Búfalo /EUA, que verificou ser queixa em $20 \%$ das consultas (THOMAS et al, 2008). Apesar disso sua significância permanece pouco compreendida. É possível dizer que a fadiga é um sintoma subjetivo, multifatorial, que engloba os âmbitos físico, emocional e cognitivo do indivíduo (CHAUDHURI, BEHAN, 2004).

\subsubsection{Fadiga na DP}

A fadiga pode ser um importante determinante da qualidade de vida $\mathrm{e}$ incapacidade física na PD, pode preceder os sintomas motores, e, é subestimada em termos de seu impacto negativo sobre o bem-estar do paciente. Em geral a fadiga é frequentemente considerada pelos pacientes com DP a ser um dos mais sintomas incapacitantes que afetam as atividades da vida diária e qualidade de vida (HALAVLIKOVA et al, 2008). 
Chaudhuri e Behan (2004) aventaram a hipótese de que a fadiga esteja relacionada a uma disfunção das alças que passam pelos núcleos da base e envolvidas em motivação e tarefas de iniciativa própria. Portanto, a fadiga poderia ser consequência em manter as tarefas físicas e mentais sustentadas. Para outros autores, além dos mecanismos aqui relatados, estaria também implicada uma disfunção primariamente motora em áreas corticais envolvidas com planejamento e execução de tarefas motoras dependentes de motivação e iniciativa própria (PAVESE et al, 2010). Embora previamente ter sido negligenciada na DP, atualmente a fadiga já pode ser considerada como um dos sintomas mais comuns, sendo mais frequente que em grupos-controle e com prevalência variando de $35.4 \mathrm{a}$ $59.1 \%$ em alguns estudos (DEL SORBO, ALBANESE, 2012; WEN et al, 2012; FABBRINI et al, 2013) e da mesma forma que a SED, a fadiga pode ser uma manifestação precoce ou mesmo pré-motora da DP (HAGELL, BRUNDIN, 2009).

Em trabalho realizado por Goulart e colaboradores (2009) com idosos portadores de DP e outro grupo sem doença neurológica ou oncológica, foi verificado que portadores de DP apresentaram os percentuais de fadiga, depressão e SED superiores aos do grupo controle: $70 \%$ vs $22 \%, 44 \%$ vs $8 \%$ e $44 \%$ vs $16 \%$, respectivamente. Não é só a prevalência de fadiga superior à da população mesma idade, mas aquela experimentada na PD parece ser qualitativamente diferente da sentida na população geral (BEISKE et al, 2010).

Em outro estudo desenvolvido com 402 indivíduos com DP, houve a inferência que a fadiga é comum nos pacientes ambulatoriais sendo considerada angustiante em cerca de um terço deles. A análise mostrou que a presença de fadiga severa foi associada ao aumento da gravidade da doença, pior qualidade de vida, comportamentos sociais e psicológicos piores, maior severidade de sintomas depressivos, e maior prevalência de distúrbios do sono noturno e SED (STROCCHI et al, 2014). A avaliação da fadiga pode ser realizada através de instrumentos uni e multidimensionais, estes têm a proposta de avaliar aspectos objetivos da fadiga, entretanto, recentemente, as pesquisas se voltam cada vez mais em relação à avaliação dos aspectos subjetivos (WHITEHEAD, 2009). A aplicação de escalas unidimensionais, como a escala de severidade de fadiga, mesmo fornecendo informações limitadas, apresenta maior sensibilidade para detectar pequenas 
variações de intensidade da fadiga, Já as escalas multidimensionais permitem avaliar diversos aspectos da fadiga, como os sociais, físicos ou cognitivos, ocorrendo, entretanto, perdem na sensibilidade diagnóstica (WHITEHEAD, 2009).

Vários estudos publicados investigaram a fadiga em PD mas muitas vezes com utilização de diferentes escalas de avaliação (DITTNER, 2004; BROWN et al, 2005). A força-tarefa da Movement Disorders Sociaty (MDS) avaliou recentemente escalas de avaliação disponíveis para a fadiga e apenas a escala de Severidade de Fadiga (Fatigue Severity Scale) foi recomendada tanto para triagem como para classificação de gravidade, pois detecta pequenas variações na sua intensidade (FRIEDMAN et al, 2010).

\subsection{Composição Corporal}

A avaliação da composição corporal tornou-se uma importante ferramenta utilizada na detecção, prevenção e no tratamento das diversas doenças crônicas, bem como em programas de emagrecimento e condicionamento físico. Desordens alimentares como obesidade e a anorexia, a sarcopenia e a osteoporose (tipificadas pela perda de massa muscular e da massa óssea, respectivamente), são problemas constantemente abordados por estudiosos e detectados por meio das técnicas de avaliação da composição corporal (KIEBZAK et al, 2000; ANDREOLI et al, 2009; NANA et al, 2015).

Diversas técnicas e metodologias indiretas são utilizadas para avaliação da composição corporal: a) antropometria; b) medidas do volume corporal; c) medidas de volume hídrico corporal, incluindo métodos de bioimpedância; d) técnicas de imagem corporal, que incluem tomografia, ressonância magnética e a DXA (Dual Xray Absorptiometry / Densitometria por emissão de raios $x$ de dupla energia), sendo este último sendo considerado padrão-ouro (ELLIS, 2001; KIEBZAK et al, 2000).

\subsubsection{Composição Corporal e Envelhecimento}

A prevalência de incapacidade e dependência funcional é maior em idosos e está intimamente associada à redução da massa muscular, que ocorre, até mesmo, 
em indivíduos saudáveis. Estudos prévios descreveram alterações da composição corporal com o envelhecimento, como redução do teor de água, aumento de gordura e declínio da massa muscular esquelética (FORBES, REINA, 1970; FRONTERA et al, 1991).

A sarcopenia parece decorrer da interação complexa de distúrbios da inervação, diminuição de hormônios, aumento de mediadores inflamatórios e alterações da ingestão protéico-calórica que ocorrem durante o envelhecimento. A perda de massa e força muscular é responsável pela redução de mobilidade e aumento da incapacidade funcional e dependência. Quando associada à fragilidade, esta perda gera custos econômicos e sociais (FOX et al, 2000).

A síndrome de fragilidade, utiliza a sarcopenia como uma das variáveis utilizadas para sua definição. Esta síndrome é altamente prevalente em idosos, conferindo maior risco para quedas, fraturas, incapacidade, hospitalização recorrente e mortalidade (MAETZLER, DREY, JACOBS, 2015); representa uma vulnerabilidade fisiológica relacionada à idade, resultado da deterioração da homeostase biológica e da capacidade do organismo de se adaptar às novas situações físicas (CRUZ-JENTOFT, 2010).

A definição da síndrome de fragilidade de acordo com o consenso Europeu (CRUZ-JENTOFT, 2010), vai além da redução da massa muscular, mas também há declínio da força muscular (medição da força manual) e da função do músculo (velocidade da marcha). Outros indicadores desta síndrome incluem perda de peso recente, especialmente da massa magra; auto-relato de fadiga; quedas freqüentes; fraqueza muscular; diminuição da velocidade da marcha e redução da atividade física, todos relacionados ao desempenho do sistema musculo-esquelético (SILVA et al, 2006).

\subsubsection{Composição Corporal na DP}

Os SM da doença de Parkinson tornam os portadores suscetíveis à má nutrição por múltiplos fatores que vão efeitos colaterais dos medicamentos e a disfagia podem limitar a ingestão de alimentos, os movimentos involuntários e o comprometimento motor associados à DP podem afetar o gasto energético 
(PETRONI et al, 2003). Nesse sentido, a avaliação da composição corporal em portadores da DP pode informar sobre a densidade mineral óssea - item mais estudado -, massa livre de gordura corporal, adiposidade, e, indiretamente, sobre o estado nutricional (PETRONI et al, 2003). As disfunções motoras como flutuações motoras, freezing, e discinesias provavelmente influem na composição corporal, provavelmente por interferir nos níveis de atividade física e mobilidade nos quadros de grau avançado da doença (KISTNER, LHOMMÉE, KRACK, 2014). Provavelmente, como uma consequência desses fatos, tais comprometimentos motores podem desempenhar um papel significativo na composição da massa corporal por interagir com a idade (ROUBENOFF, HUGHES, 2000).

Poehlman e colaboradores (1995) estudaram a taxa metabólica basal e composição corporal através do DXA em oito pacientes com DP e 34 controles saudáveis idosos e verificaram níveis mais baixos de massa livre de gordura nos oito indivíduos com DP, mas as taxas metabólicas em repouso foram semelhantes aos controles saudáveis, sugerindo um estado hipermetabólico, o que poderia contribuir para a sarcopenia acelerada (POEHLMAN et al, 1995, BAUMGARTNER, 2000). Em outro estudo, esses mesmos autores encontraram que o gasto energético diário foi menor nos pacientes com DP que respondem a L-dopa, inferindo ser devido à redução do gasto de energia com a melhora motora (TOTH, FISHMAN, POEHLMAN, 1997).

Por sua vez, o estudo de Yilmaz e colaboradores (2015) com 73 portadores da DP, verificou uma importante redução de massa magra em relação ao grupo controle de 71 indivíduos. O peso corporal total, foi também foi maior nos saudáveis, mas já esta diferença não foi estatisticamente significante. Esse estudo indicou que a sarcopenia pode ser vista mais comumente em pacientes com DP, especialmente naqueles que são idosos. 


\section{MATERIAIS E MÉTODOS}

\subsection{Delinemento do Estudo}

A pesquisa caracterizou-se como um estudo transversal do tipo descritivo correlacional (THOMAS, NELSON, 2002).

\subsection{Local do Estudo}

As avaliações antropométricas e da composição corporal foram realizadas no Laboratório de Imagem da Faculdade de Educação Física (FEF) da Universidade de Brasília (UnB). As entrevistas foram realizadas no Ambulatório de Medicina do Sono do Hospital Universitário de Brasília (HUB) ou na sala de avaliação clínica do Centro Olímpico da FEF.

\subsection{Amostra}

Participaram como voluntários deste estudo 48 indivíduos de ambos os sexos com idades entre 49 e 84 anos, diagnosticados com DP por um médico neurologista, de acordo com os critérios do banco de cérebro de Londres e com classificação da doença entre 1 e 3 (escala de HOEHN \& YAHR).

Os critérios de inclusão para a participação no estudo foram:
a) Voluntários do gênero masculino e feminino portadores da DP;
b) Idade entre 45 e 85 anos de idade;
c) Apresentar classificação entre 1 e 3 na escala de Hoehn e Yahr modificada no estágio da doença na avaliação neurológica;
d) Concordar em responder aos questionários e realizar o DXA.

Os critérios de exclusão foram:

a) Ter sido submetido a artroplastia total ou parcial; 
b) Ser portador de osteossíntese de qualquer natureza;

c) Ter sofrido fratura ou lesão muscular nos últimos 6 meses;

d) Apresentar amputação de membros superiores ou inferiores;

e) Negar-se a assinar o TCLE.

\subsection{Aspectos éticos}

Esta pesquisa foi aprovada pelo (Projeto de $\mathrm{n}$-034/11) pelo Comitê de Ética em Pesquisa do governo do Distrito Federal, tendo por base a resolução 196/96 CNS/MS. A coleta de dados foi iniciada após a aprovação do referido comitê. Cada paciente foi identificado por um número, mantendo, dessa forma, o anonimato. Todos os procedimentos do estudo, bem como o TCLE, foram explicados aos voluntários, antes de sua assinatura. Cada voluntário recebeu uma cópia do TCLE assinado pela pesquisadora.

\subsection{Procedimento para a Coleta de Dados}

Os voluntários da pesquisa possuíam vínculo com o Hospital Universitário de Brasília e / ou com a Faculdade de Educação Física, ambos da Universidade de Brasília (UnB) e foram convidados pela pesquisadora a participar do estudo. Após triagem inicial, com aplicação dos critérios de inclusão e exclusão, 48 voluntários foram incluídos na amostra. Todos os indivíduos foram informados sobre os objetivos, procedimentos, possíveis desconfortos, riscos e benefícios do estudo. Após a concordância em participar da pesquisa, todos os participantes assinaram o TCLE e foram submetidos a avaliação neurológica, composta por anamnese, exame físico e neurológico, entrevista composta por dois questionários, bem como ao exame de imagem, para a avaliação da composição corporal.

\subsection{Instrumentos de Avaliação}




\section{- Anamnese}

Alguns dados da anamnese foram respondidos pelo paciente e/ou acompanhante (cuidador ou familiar) do voluntário da pesquisa, na ficha de identificação (Apêndice A), com dados referentes à identificação e dados sobre o diagnóstico, sintomas de início da doença e atuais, lado predominante dos sintomas, informações sobre a prática de atividade física, lista das medicações em uso. Na consulta médica houve estadiamento do grau de comprometimento (HY) e foram realizadas as entrevistas para avaliar a SED e o grau de Fadiga através das escalas respectivas: de sonolência de Epworth - Epworth Sleepiness Scale e a da Severidade da Fadiga - Fatigue Severity Scale. Essas avaliações foram realizadas na maioria das vezes em dois encontros.

\section{- Escala de Estadiamento de Hoehn \& Yahr modificada}

A escala de estadiamento modificada de Hoehn e Yahr (HY - Degree of Disability Scale) faz uma graduação motora dos indivíduos com DP que é capaz de indicar o estado geral do portador da doença de forma rápida e prática. Sua forma modificada compreende sete estágios de classificação para avaliar a gravidade da DP e abrange, essencialmente, medidas globais de sinais e sintomas que permitem classificar o indivíduo quanto ao nível de incapacidade (GOETZ et al, 2004). Os indivíduos classificados nos estágios de 1 a 3 apresentam incapacidade leve a moderada, enquanto os que estão nos estágios 4 e 5 apresentam incapacidade grave. A classificação foi realizada através do exame neurológico feito na consulta médica no HUB ou no CO/ FEF.

\section{- Escala da Severidade da Fadiga (ESF)}

A ESF tem a intenção de identificar e quantificar a intensidade da fadiga, além de avaliar o impacto deste sintoma na vida diária do paciente (FRIEDMAN et al, 2010). Esta escala é composta por nove itens, cada um variando de 1 a 7 . 0 indivíduo é indagado sobre cada uma das nove afirmações, e deve escolher para cada uma delas um número de 1 a 7 que melhor descreve o grau de concordância 
ou discordância para a referida afirmação: 1 indica que o paciente discorda completamente e 7 indica que ele concorda plenamente com a afirmação feita. Os escores variam de 9 a 63, sendo considerado que escore maior ou igual a 28, é indicativo de fadiga. A partir de 28 pontos quanto mais alto o escore maior o grau de sua severidade. O questionário foi aplicado pela pesquisadora em ambiente silencioso e sem distratores na consulta médica.

\section{- Escala de Sonolência de Epworth (ESE)}

Formulário mundialmente utilizado para avaliar Sonolência Excessiva Diurna (SED) e tem sido amplamente utilizada na Doença de Parkinson para avaliar a intensidade da sonolência diurna (KUMAR, 2003, BERTOLAZI, 2008). A escala tem o objetivo de avaliar a possibilidade do indivíduo cochilar em oito situações com capacidades diferentes de induzir sono. As respostas variam de zero, nenhuma probabilidade, a 3 que corresponde a alta probabilidade de adormecer. $\mathrm{O}$ escore varia de 0 a 24, e a pontuação acima de 10 pontos caracteriza sonolência excessiva diurna. O questionário foi aplicado pela pesquisadora em ambiente silencioso e sem distratores na consulta médica. A escala também foi respondida por acompanhante durante a consulta médica ou por familiar via telefone ou pessoalmente.

\section{- Variáveis Antropométricas}

A estatura foi medida por meio de estadiômetro da marca Country Tecnology ${ }^{\circledR}$, com resolução de um centímetro. As mensurações foram tomadas em triplicata e a média da estatura foi registrada (LOHMAN, 1991).

A massa corporal foi mensurada por meio de uma balança Filizola ${ }^{\circledR}$ eletrônica/ digital, com resolução de 100 gramas (modelo "PersonalLine").

Para a medida da massa corporal, o participante esteve em pé, com pés unidos e voltados para frente, ombros relaxados e membros superiores ao longo do corpo, estando o plano de Frankfurt (linha imaginária que passa pelo ponto mais baixo do bordo inferior da órbita direita e pelo ponto mais alto do bordo superior do meato acústico externo direito em nível do trago) rigorosamente posicionado. Para 
registro da estatura, foi solicitado a realização de uma inspiração máxima, seguida de apnéia, para então efetuar-se a leitura. Em seguida o índice de massa corporal (IMC) foi obtido pela divisão da massa corporal $(\mathrm{kg})$, pela estatura elevada ao quadrado $\left(\mathrm{m}^{2}\right)$. A partir do resultado classificou-se o grupo de voluntários de acordo com o IMC, segundo a classificação da OMS: Magreza severa <16.00; Magreza Moderada 16.00 - 16.99; Magreza leve 17.00 - 18.49; Baixo peso <18.50; Peso Normal 18.50 - 24.99; Sobrepeso $\geq 25.00$; Pré - Obeso 25.00 - 29.99; Obeso $\geq 30.00$ (Obeso classe I 30.00 - 34.99; Obeso classe II 35.00 - 39.99 e Obeso classe III $\geq 40.00$ ). A classificação internacional do baixo peso, sobrepeso e obesidade adulta, de acordo com o IMC (WHO, 2004)

\section{- Composição Corporal}

A composição corporal foi mensurada através da Absorciometria com Raios-X de Dupla Energia (DXA), utilizando o densitômetro ósseo da marca General Eletric GE Healthcare ${ }^{\circledR}$, modelo Lunar Prodygy $\operatorname{Pro}^{T M}$ (GE Lunar, Madison, WI). O DXA compreende uma varredura de corpo inteiro do indivíduo e proporciona uma avaliação completa da densidade óssea, massa de gordura e massa magra. $O$ indivíduo foi posicionado no equipamento em decúbito dorsal, com pernas e braços estendidos juntos do corpo. Os dados foram analisados por meio do software GE Medical Systems Lunar ${ }^{\mathrm{TM}}$. 


\subsection{Tratamento Estatístico}

A estatística descritiva foi realizada por meio das medidas de média e desvio padrão. Este estudo analisou a influência de medidas de composição corporal na sonolência e na fadiga de pacientes com a doença de Parkinson. Nesse sentido, as variáveis independentes foram: percentual de gordura, massa total, massa de gordura e massa livre de gordura. As variáveis dependentes foram: sonolência e fadiga. Foram utilizadas como co-variáveis a idade, o sexo e o nível de acometimento.

A normalidade dos dados foi analisada através do teste de KolmogorovSmirnov. As variáveis de caracterização amostral nas quais se atestou a normalidade (estatura, IMC e percentual de gordura) foram analisadas quanto suas diferenças entre sexo e rígido/tremulante através do teste $T$ independente, e quanto suas diferenças entre níveis de acometimento através da análise de variância ANOVA de um fator, com posthoc de Bonferroni. As variáveis nas quais não se atestou a normalidade (idade e massa corporal) foram analisadas quanto suas diferenças entre sexo e forma predominante de apresentação da doença - forma rígida ou tremulante - através do teste de Mann-Whitney $\mathrm{U}$, e quanto suas diferenças entre níveis de acometimento através do teste de Kruskal-Wallis.

As relações entre as variáveis independentes (percentual de gordura, massa total, massa de gordura e massa livre de gordura e IMC) e as variáveis dependentes (sonolência e fadiga) foram determinadas através da Correlação de Spearman. Este teste foi escolhido em virtude da origem dos dados de fadiga e sonolência, advindos de questionários. Diferenças na composição corporal de rígidos e tremulantes foram investigadas através do teste $\mathrm{T}$ independente. As diferenças na sonolência e na fadiga entre rígidos e tremulantes foram investigadas através do teste de MannWhitney U. As análises estatísticas foram realizadas por meio do programa SPSS (Statistical Package for Social Sciences) versão 21.0. O nível de significância adotado foi de $5 \%(p<0,05)$. 


\section{RESULTADOS}

Fizeram parte deste estudo 48 indivíduos com DP, sendo 37 homens e 11 mulheres. As características da amostra agrupadas por sexo são apresentadas na tabela 1. Observou-se uma diferença significativa entre homens e mulheres nas variáveis estatura, massa corporal e percentual de gordura $(p<0,001)$.

Tabela 1 - Características da amostra agrupadas por sexo expressas em média e desvio padrão.

\begin{tabular}{lccc}
\hline & Homens $\mathbf{( n = 3 7 )}$ & Mulheres (n = 11) & p \\
\hline Idade (anos) & $66,18 \pm 9,25$ & $64,03 \pm 0,19$ & 0,402 \\
Estatura (m) & $1,69 \pm 0,07$ & $1,52 \pm 0,05$ & $<0,001$ \\
Massa Corporal (kg) & $77,10 \pm 13,54$ & $61,45 \pm 7,20$ & $<0,001$ \\
IMC (kg/m2) & $26,82 \pm 4,05$ & $26,78 \pm 3,56$ & 0,974 \\
Percentual de gordura (\%) & $30,67 \pm 8,38$ & $41,72 \pm 6,54$ & $<0,001$ \\
\hline
\end{tabular}

Em relação ao nível de acometimento analisado pela escala de Hoehn \& Yahr, cinco indivíduos encontravam-se no estágio 1, 18 no estágio 1,5, 19 no estágio 2, dois no estágio 2,5 e quatro no estágio 3 (tabela 2). Não houve diferença em nenhuma variável entre os diferentes graus de acometimento.

Tabela 2 - Características da amostra agrupadas pelo nível de acometimento expressas em média e desvio padrão.

\begin{tabular}{lcccccc}
\hline & $\begin{array}{c}\text { Nível 1 } \\
(\mathbf{n}=\mathbf{5})\end{array}$ & $\begin{array}{c}\text { Nível 1,5 } \\
(\mathbf{n}=\mathbf{1 8})\end{array}$ & $\begin{array}{c}\text { Nível 2 } \\
(\mathbf{n}=\mathbf{1 9})\end{array}$ & $\begin{array}{c}\text { Nível 2,5 } \\
(\mathbf{n}=\mathbf{2})\end{array}$ & $\begin{array}{c}\text { Nível 3 } \\
(\mathbf{n}=\mathbf{4})\end{array}$ & p \\
\hline Idade (anos) & $63,12 \pm 4,97$ & $62,96 \pm 8,42$ & $67,03 \pm 10,29$ & $68,95 \pm 6,01$ & $73,78 \pm 8,75$ & 0,142 \\
& & & & & & \\
Estatura (m) & $1,67 \pm 0,04$ & $1,65 \pm 0,09$ & $1,64 \pm 0,10$ & $1,73 \pm 0,01$ & $1,71 \pm 0,12$ & 0,592 \\
& & & & & & \\
$\begin{array}{l}\text { Massa Corporal } \\
\text { (kg) }\end{array}$ & $73,12 \pm 7,63$ & $70,21 \pm 12,85$ & $76,24 \pm 16,63$ & $82,10 \pm 20,36$ & $75,58 \pm 9,21$ & 0,315 \\
IMC (kg/m2) & $26,04 \pm 1,65$ & $25,61 \pm 3,16$ & $28,26 \pm 4,72$ & $27,49 \pm 7,25$ & $26,02 \pm 2,24$ & 0,326 \\
& & & & & & \\
$\begin{array}{l}\text { Percentual de } \\
\text { gordura (\%) }\end{array}$ & $28,64 \pm 7,48$ & $31,45 \pm 9,98$ & $35,23 \pm 9,53$ & $30,65 \pm 4,88$ & $35,68 \pm 5,93$ & 0,535 \\
\hline
\end{tabular}


As diferenças nas características amostrais entre a FR e FT são apresentados na tabela 3 . O pacientes com a FR apresentaram massa corporal $(p=$ $0,014)$, IMC $(p=0,040)$ e percentual de gordura $(p=0,025)$ significativamente superiores aos dos indivíduos com a FT.

Tabela 3 - Características da amostra agrupadas por forma rígida (FR) ou tremulante (FT) expressas em média e desvio padrão.

\begin{tabular}{lccc}
\hline & FR $(\mathbf{n}=\mathbf{2 6})$ & FT $(\mathbf{n}=\mathbf{2 2})$ & $\mathbf{p}$ \\
\hline Idade (anos) & $65,62 \pm 8,79$ & $65,88 \pm 9,84$ & 0,923 \\
Estatura (m) & $1,67 \pm 0,10$ & $1,64 \pm 0,09$ & 0,223 \\
Massa Corporal (kg) & $78,34 \pm 13,84$ & $68,53 \pm 12,44$ & 0,014 \\
IMC (kg/m2) & $27,87 \pm 3,36$ & $25,56 \pm 4,23$ & 0,040 \\
Percentual de gordura (\%) & $35,67 \pm 6,71$ & $29,78 \pm 10,72$ & 0,025 \\
\hline
\end{tabular}

Os resultados da análise da composição corporal dos participantes são apresentados na tabela 4 em média e desvio padrão. Os resultados da análise da sonolência e da fadiga, por serem advindos de questionários, são apresentados na tabela 5 em média, desvio padrão, mediana, máximo e mínimo. Os resultados da análise das diferenças das variáveis de composição corporal, sonolência e fadiga entre indivíduos com a FR e a FT são expostos na tabela 6. Os pacientes rígidos apresentaram percentual de gordura significativamente maior $(p=0,025)$ que os portadores da FT. Foram encontradas também diferenças significativas que apontam uma maior massa total em pacientes rígidos quando comparados aos tremulantes ( $p$ $=0,022$ ). Além disso, pacientes rígidos demonstram fadiga significativamente maior do que pacientes tremulantes $(p<0,001)$. 
Tabela 4 - Variáveis de composição corporal expressas em média e desvio padrão.

\begin{tabular}{ll}
\hline Percentual de Gordura (\%) & $32,97 \pm 9,17$ \\
Massa Total $(\mathrm{kg})$ & $73,14 \pm 13,89$ \\
Massa Gorda $(\mathrm{kg})$ & $22,62 \pm 9,47$ \\
Massa Livre de Gordura $(\mathrm{kg})$ & $46,34 \pm 10,59$ \\
\hline
\end{tabular}

Tabela 5 - Escores de Sonolência e Fadiga expressas em média, desvio padrão, mediana, mínimo e máximo.

\begin{tabular}{lccccc}
\hline & Média & $\begin{array}{l}\text { Desvio } \\
\text { Padrão }\end{array}$ & Mediana & Mínimo & Máximo \\
\hline $\begin{array}{l}\text { Sonolência } \\
\text { (Epworth 0 - 24) }\end{array}$ & 10,88 & 4,21 & 10,00 & 00 & 21 \\
$\begin{array}{l}\text { Fadiga } \\
\text { (ESF 9 - 63) }\end{array}$ & 36,21 & 13,97 & 34,50 & 12 & 62 \\
\hline
\end{tabular}

Tabela 6 - Variáveis de composição corporal, sonolência e fadiga diferenciadas para FR ou FT expressas em média e desvio padrão.

\begin{tabular}{lccc}
\hline & FR $(\mathbf{n}=\mathbf{2 6})$ & FT $(\mathbf{n}=\mathbf{2 2})$ & $\mathbf{p}$ \\
\hline Percentual de Gordura (\%) & $35,67 \pm 6,71$ & $29,78 \pm 10,72$ & 0,025 \\
Massa Total (kg) & $77,32 \pm 13,98$ & $68,20 \pm 12,33$ & 0,022 \\
Massa Gorda (kg) & $24,95 \pm 9,63$ & $19,87 \pm 8,70$ & 0,063 \\
Massa Livre de Gordura (kg) & $47,93 \pm 9,83$ & $44,46 \pm 11,36$ & 0,262 \\
Sonolência & $11,73 \pm 4,82$ & $9,86 \pm 3,15$ & 0,127 \\
Fadiga & $42,65 \pm 13,59$ & $28,59 \pm 10,25$ & $<0,001$ \\
\hline
\end{tabular}

A relação entre as variáveis de composição corporal, a sonolência e a fadiga, analisada através da correlação de Spearman, é apresentada na tabela 7. Há 
uma correlação positiva e significante entre a massa total e a sonolência $(p=0,037)$, sugerindo que o indivíduo com maior massa livre de gordura, possuiria maior sonolência. Nota-se também uma correlação positiva e significativa entre a massa gorda e a fadiga ( $p=0,027)$, demonstrando que quanto maior a massa gorda, maior a fadiga. Além disso, há uma correlação positiva e significativa entre a massa livre de gordura e a sonolência $(p=0,048)$. Portanto, o indivíduo com uma maior massa livre de gordura apresentaria uma maior sonolência. Essa relação porém foi refutada na análise dos questionários com a percepção da sonolência observada pelos familiares.

Apesar de não significante, a correlação positiva e tendendo a significância entre o percentual de gordura e a fadiga $(p=0,059)$ pode indicar que quanto maior $o$ percentual de gordura no indivíduo com a Doença de Parkinson, maior a fadiga. $\mathrm{Da}$ mesma forma, a correlação positiva e tendendo a significância entre o IMC e a Fadiga ( $p=0,055$ ), também permite afirmar que o indivíduo com DP com maior IMC apresentará uma maior fadiga. Essas relações estão expressas nas tabelas 7 e 8.

Tabela 7 - Relações entre fadiga, sonolência e composição corporal demonstradas em Rô de Spearman e significância.

\section{Sonolência $\quad$ Fadiga}

\begin{tabular}{lcccc}
\hline & Sonolência & \multicolumn{2}{c}{ Fadiga } \\
& Rô de Spearman & $\mathbf{p}$ & Rô de Spearman & $\mathbf{p}$ \\
\hline Percentual de Gordura & $-0,39$ & 0,791 & 0,275 & 0,059 \\
Massa Total & 0,302 & 0,037 & 0,180 & 0,222 \\
Massa Gorda & 0,104 & 0,482 & 0,318 & 0,027 \\
Massa Livre de Gordura & 0,286 & 0,048 & $-0,043$ & 0,769 \\
IMC & 0,249 & 0,087 & 0,278 & 0,055
\end{tabular}

A análise da diferença na percepção de sonolência sentida pelo paciente e relatada pelo familiar foi realizada através de um teste T pareado, em 23 pacientes. Os resultados apontam que os familiares percebem uma sonolência significativamente superior do que os próprios pacientes $(p<0,001)$, conforme demonstrado a seguir 
Tabela 8 - Percepção de sonolência sentida pelo paciente e relatada pelo familiar.

Paciente $(n=23) \quad$ Familiar $(n=23) \quad p$

Sonolência $\quad 10,78 \pm 3,93 \quad 14,74 \pm 4,55 \quad<0,001$

A relação entre a sonolência percebida pelo familiar e as variáveis de composição corporal foi analisada através da Correlação de Spearman. A sonolência percebida pelo familiar não apresenta correlação significativa com nenhuma variável, ao contrário da percebida pelo próprio paciente. Estes resultados são expressos na tabela 9.

Tabela 9 - Relação entre sonolência percebida pelo familiar de 23 sujeitos com a composição corporal demonstradas em Rô de Spearman e significância.

\begin{tabular}{lcc}
\hline & \multicolumn{2}{c}{ Sonolência percebida pelo familiar } \\
\cline { 2 - 3 } & Rô de Spearman & $\mathbf{p}$ \\
Percentual de Gordura & 0,102 & 0,645 \\
Massa Total & 0,279 & 0,198 \\
Massa Gorda & 0,158 & 0,472 \\
Massa Livre de Gordura & 0,175 & 0,425 \\
IMC & 0,338 & 0,115
\end{tabular}

A comparação das variáveis de caracterização amostral dos indivíduos da forma rígida e da tremulante que possuíam o relato do familiar foi realizada através do teste $\mathrm{T}$ independente para as variáveis nas quais foi atestada a normalidade. As variáveis nas quais não se atestou a normalidade foram analisadas quanto suas diferenças entre FR e FT através do teste de Mann-Whitney U. Diferenças na composição corporal de rígidos e tremulantes foram investigadas através do teste $\mathrm{T}$ independente. As diferenças na sonolência e na fadiga entre rígidos e tremulantes foram investigadas através do teste de Mann-Whitney $U$.

Os resultados dos 23 indivíduos que possuíam o relato do familiar estão expostos na Tabela 09 e na Tabela 10. Não houve diferença entre rígidos e tremulantes em nenhuma variável de caracterização amostral. As variáveis de composição corporal, sonolência percebida pelo próprio paciente e sonolência 
percebida pelo familiar não se diferenciaram significativamente entre rígidos e tremulantes. Entretanto, pacientes rígidos apresentaram a fadiga significativamente superior que pacientes tremulantes $(p=0,041)$, resultado semelhante ao obtido na população dos 48 indivíduos.

Na tabela 11 é demonstrado o comparativo das variáveis da composição corporal entre as FR e FT dos 23 pacientes, com a inclusão da sonolência observada pelo familiar.

Tabela 10 - Características dos 23 indivíduos que possuíam o relato do familiar, expressos em média e desvio padrão.

\begin{tabular}{lccc}
\hline & FR $(\mathbf{n}=\mathbf{1 1})$ & $\mathbf{F T}(\mathbf{n}=\mathbf{1 2})$ & $\mathbf{p}$ \\
\hline Idade (anos) & $69,32 \pm 8,42$ & $66,68 \pm 11,39$ & 0,538 \\
Estatura $(\mathrm{m})$ & $1,65 \pm 0,12$ & $1,66 \pm 0,09$ & 0,961 \\
Massa Corporal $(\mathrm{kg})$ & $76,07 \pm 16,13$ & $73,38 \pm 12,83$ & 0,660 \\
IMC $(\mathrm{kg} / \mathrm{m} 2)$ & $27,68 \pm 4,36$ & $26,85 \pm 4,74$ & 0,666 \\
Percentual de gordura (\%) & $36,56 \pm 7,01$ & $29,09 \pm 12,08$ & 0,088 \\
\hline
\end{tabular}

Tabela 11 - Variáveis de composição corporal, sonolência e fadiga diferenciadas por rígidos ou tremulantes expressas em média e desvio padrão.

\begin{tabular}{lccc}
\hline & FR $(\mathbf{n}=\mathbf{1 1})$ & FT (n=12) & p \\
\hline Percentual de Gordura (\%) & $36,56 \pm 7,01$ & $29,09 \pm 12,08$ & 0,088 \\
Massa Total (kg) & $75,05 \pm 16,31$ & $73,03 \pm 12,65$ & 0,742 \\
Massa Gorda (kg) & $26,30 \pm 6,92$ & $21,06 \pm 10,44$ & 0,175 \\
Massa Livre de Gordura (kg) & $45,99 \pm 11,73$ & $49,33 \pm 8,65$ & 0,443 \\
Sonolência & $10,73 \pm 4,43$ & $10,83 \pm 3,61$ & 0,950 \\
Sonolência Percebida pelo Familiar & $15,82 \pm 4,77$ & $13,75 \pm 4,31$ & 0,287 \\
Fadiga & $44,45 \pm 16,77$ & $31,67 \pm 11$ & 0,041 \\
\hline
\end{tabular}




\section{DISCUSSÃO}

A DP é uma patologia que pode sofrer um desequilíbrio na composição corporal uma vez que os sintomas da doença, como a disfagia e efeitos colaterais das medicações podem limitar a ingestão de alimentos; assim como a prórpia disfunção motora pode similarmente afetar o balanço energético (KISTNER, LHOMMÉE, KRACK, 2014). Os sintomas motores como rigidez em bloco, fenômeno do congelamento e discinesias são susceptíveis em influenciar a composição corporal, tanto pelo seu incremento de gasto calórico - caso das discinesias - como pelos baixos níveis de atividade física, em especial naqueles com DP com o subtipo motor rígido ou em estágio avançado da doença (PETRONI et al, 2003).

A análise da composição corporal pode fornecer informações sobre a densidade mineral óssea (DMO), massa magra e adiposidade e, indiretamente, sobre o estado nutricional do indivíduo; nesse sentido, há escassos dados de literatura quando se trata de portadores da DP. A associação entre a composição corporal e sintomas não motores como fadiga e SED, com o adendo da diferenciação entre os fenótipos da DP (forma de predomínio rígido ou tremulante) não foi motivo de publicação até esse estudo,

Alguns estudos indicam que a fadiga é um SNM frequente na DP, assim como na síndrome de fragilidade em idosos sem doença neurodegenerativa. No caso da Doença de Parkinson, muitas pesquisas sugerem que a fadiga não estaria relacionada à sonolência excessiva ou distúrbio do sono, indicando que pode ser um sintoma primário da doença (HALAVLIKOVA et al, 2008). A SED, por sua vez, é um sintoma que vem alcançando evidências mais robustas em ser um sintoma independente da DP, inclusive com alguns indícios da FR ter maior suscetilidade de tal acometimento (HOGLUND et al, 2015).

Os achados dessa pesquisa sugerem que a avaliação da composição corporal apresenta-se como uma necessidade na população com a DP. Os resultados dos estudos existentes evidenciam uma variabilidade importante em gênero e idade, no grau de acometimento baseado na classificação de HY e no tempo de doença. Do mesmo modo, os dados da composição corporal também 
apresentaram discordância nos resultados dos estudos, uma vez que esses foram realizados em três continentes diferentes, devendo-se, portanto, considerar as particularidades étnicas e culturais dessas populações (TOTH, FISHMAN, POEHLMAN, 1997; REVILLA et al, 1998; PETRONI et al, 2003; FERNANDEZ et al, 2007).

Ao relacionar os indivíduos ao grau de comprometimento, é percebido que há um IMC semelhante, mas um maior diferencial no que tange ao aumento do percentual de gordura naqueles que se encontram no estágio 3 em relação ao 1 na escala de HY. No entanto não é cabível fazer afirmações visto o pequeno número de indivíduos nestes estágios. O percentual de gordura foi maior no sexo feminino, ainda que o IMC se assemelhe entre os gêneros. $O$ aumento da massa corporal observado nesse estudo encontrou semelhança com o estudo de Petroni et. al (2003), onde foi verificado excesso de adiposidade em ambos, porém o grupo italiano encontrou a redução de massa livre de gordura (obesidade sarcopênica) em sua amostra.

Ademais, nenhum dos trabalhos realizados com a mensuração da composição corporal em portadores da DP avaliou separadamente os subtipos motores rígido e tremulante, assim como em nenhum houve investigação de SNM como a fadiga e a SED. O resultado encontrado nesse estudo, referente ao aumento de percentual de gordura na FR associado a um aumento significativo dos níveis de fadiga, pode ser considerado como uma limitação auto-imposta pela própria fadiga, aumentando a dificuldade deambulatória dos indivíduos, diminuindo a vontade em realizar exercícios, o que contribui para o aumento da adiposidade corporal.

A prevalência de fadiga encontrada na presente pesquisa foi semelhante a de estudos prévios (DEL SORBO, ALBANESE, 2012; WEN et al, 2012; FABBRINI et al, 2013). Por sua vez, os resultados da pesquisa de Goulart et. al (2009) que verificou um percentual de $70 \%$ na fadiga e $44 \%$ na sonolência, assemelharam-se aos resultados desse estudo, onde encontramos $64,5 \%$ na fadiga e 43,75 na sonolência. Duas particularidades se evidenciam nessa pesquisa, a presença da diferenciação fenotípica e a avaliação da escala da sonolência excessiva diurna preenchida pelo familiar. Entre os 48 pacientes, 26 foram classificados como rígidos 
e 22 como tremulantes. Na FR verificou-se uma maior prevalência dos SNM, onde $67 \%$ dos indivíduos apresentaram fadiga e $62 \%$ apresentaram SED.

A associação entre a sonolência excessiva diurna e o aumento da massa corporal e da massa livre de gordura foi verificada ao considerar os escores da escala de sonolência de Epworth dos 48 sujeitos da pesquisa. Porém destes indivíduos que fizeram o auto-relato, houve familiares de 23 portadores que também preencheram a escala, e ao comparar seus resultados com os dos portadores da DP, apenas um deles não aumentou a pontuação do indivíduo acometido pela doença. Indicando que provavelmente os portadores da DP subestimem seu grau de SED, bem como o risco que isso representa.

A diferença na percepção da sonolência foi estatisticamente significante $(p<0,001)$ entre os indivíduos acometidos e seus respectivos familiares. Além disso, no grupo de 23 participantes em que o familiar fez a avaliação objetiva, foram realizadas correlações com as variáveis de composição corporal, fadiga e subtipo motor FR ou FT, não havendo correlação entre nenhuma das variáveis. No que se refere à fadiga, o grupo de 23 indivíduos apresentou um resultado semelhante ao grupo dos 48 , sendo este resultado estatisticamente significante $(p<0,041)$. Ressalta-se que essa fadiga também está associada a um maior percentual de gordura e à FR da doença. 


\section{CONCLUSÃO}

Os resultados desse estudo mostraram uma relação significante entre a forma rígida da DP com maior percentual de gordura corporal e IMC na comparação com a FT. Igualmente foi verificado que os níveis de fadiga estavam bem mais elevados na FR. O pequeno número de participantes no estágio 1 e 3 na escala de Hoehn \& Yahr foi um fator limitante para relacionar a composição corporal e os SNM por fase da doença.

A divergência entre a percepção da sonolência apresentada pelos portadores da DP e a observação objetiva de seus familiares, demonstram que possivelmente a SED mensurada por meio da escala de Epworth seja subestimada pelos pacientes, sugerindo que esse questionário seja realizado também por um familiar em relação à presença de sonolência diurna do portador da DP.

Em razão desses achados sugere-se que mais estudos sejam realizados em relação à composição corporal e os fenótipos da DP, associando à presença de sintomas motores e de SNM, e, desse modo ampliar os conhecimentos em busca de intervenções mais direcionadas ao subtipo motor, incluindo recursos terapêuticos não farmacológicos. 


\section{REFERÊNCIAS}

ABBOT RD, et al. Excessive daytime sleepness and subsequent development of Parkinson disease. Neurology 2005; v.65, p. 1442-6.

ADLER CH. Non motor complications in Parkinson's Disease. Movement Disorder 2005; 20 (suppl 11): S23-S29.

ANDREOLI A, et al. Body composition assessment by dual-energy X-ray absorptiometry (DXA). Radiol med 2009;114:286-300.

ASCHERIO A, et al. Caffeine, postmenopausal estrogen, and risk of Parkinson's Disease. Neurology 2003; v. 60, p. 790-795.

BARBOSA, M. T, et al. Parkinsonism and Parkinson's disease in the elderly: A community-based survey in Brazil (the Bambuí Study). Movement Disorders 2006; 21(6), 800-808.

BAUMGARTNER RN. Body composition in healthy aging. Ann NYAcad Sci 2000; 904:437-448.

BEISKE AG, et al. Fatigue in Parkinson's disease: prevalence and associated factors. Mov Disord 2010; 25:2456-2460.

BERTOLAZI AN. Tradução, Adaptação cultural e validação de dois instrumentos de avaliação do sono: Escala de sonolência de Epworth e Índice de Qualidade de Sono de Pittsburgh. Porto Alegre, 2008.

BERARDELLI A, et al. Pathophysiology of bradykinesia in Parkinson's disease. Brain $2001 ; 124: 2131-46$.

BEZARD E, GROSS CE, BROTCHIE JM. Presymptomatic compensation in Parkinson's disease is not dopamine-mediated. Trends in Neuroscience 2003; 26 (4):215-221.

BRAAK H, et al. Staging of brain pathology related to sporadic Parkinson's disease. Neurobiol Aging 2003; 24:197-211.

BRAAK $\mathrm{H}$, et al. Stages in the development of Parkinson's disease-related pathology. Cell Tissue Research 2004; 318: 121-134.

BROWN RG, et al. The Parkinson fatigue scale. Parkinsonism Relat Disord 2005; $11: 49-55$.

BRUCKI SMD, et al. Sugestöes para o uso do mini-exame do estado mental no Brasil. Arquivos de Neuropsiquiatria. 2003; Vol.61, pp :777-81. 
CHAUDHURI A, BEHAN PO. Fatigue in neurological disorders. Lancet 2004; v.20, n.363, p.978-88.

CHAUDHURI KR, et al. The Parkinson's disease sleep scale: a new instrument for assessing sleep and nocturnal disability in Parkinson's disease $\mathrm{J}$ Neurol Neurosurg Psychiatry 2002; 73:629-635

CHAUDHURI KR, HEALY DG, SCHAPIRA AH, National Institute for Clinical Excellence. Non-motor symptoms of Parkinson's disease: diagnosis and management. Lancet Neurol 2006; 5:235-45.

CHAUDHURI KR, et al. An international multicentre pilot study of the first comprehensive self-completed non-motor symptoms questionnaire for Parkinson's disease: the NMSQuest study. Mov Disord 2006; 21:916-23.

CHAUDHURI KR, NAIDU Y. Early Parkinson's Disease and non-motor issues. Journal of Neurology 2008; 255 (suppl 5): 33-38.

CHEN H, et al. Research on the Premotor Symptoms of Parkinson's Disease: Clinical and Etiological Implications. Environ Health Perspect 2013; v.121, n.11-12.

CHUDLER EH, DONG WK. The role of the basal ganglia in nociception and pain. Pain 1995;60:3-38.

CRIZZLE AM, et al. Is physical exercise beneficial for persons with Parkinson's disease? Clinical Journal of Sport Medicine 2006; Vol.16,pp: 422-425.

CROWLEY K. Sleep and sleep disorders in older adults. Neuropsy-chol. Rev. 2011; $21(1) 41-53$.

CRUZ-JENTOFT AJ, et al. Sarcopenia: European consensus on definition and diagnosis: report of the EuropeanWorking Group on Sarcopenia in Older People. Age Ageing 2010; 39(4):412-423.

CUMMINGS JL. Dementia with Lewy body: molecular pathogenesis and implications for classification. J Geriatr Psychiatry Neural 2004; 17:112-119.

DE BOER, et al. Quality of life in patients with Parkinson's disease: development of a questionnaire. J Neurol Neurosurg Psychiatry 1996; 61: 70-4.

DEL SORBO $F$, ALBANESE A. Clinical management of pain and fatigue in Parkinson's Disease. Parkinsonism Relat Disord 2012; v.18, S1, S233-S236.

DICKSON DW et al. Neuropathological assessment of Parkinson's disease: refining the diagnostic criteria. Lancet Neurol 2009;8:1150-1157.

DITTNER AJ, WESSELY SC, BROWN RG. The assessment of fatigue: a practical guide for clinicians and researchers. J Psychosom Res 2004; 56:157-70. 
ELLIS KJ. Selected body composition methods can be used in field studies. J Nutr 2001; 131:1589S-1595S.

ENSRUD KE, et al Sleep Disturbances and Frailty Status in Older Community Dwelling Men. J Am Geriatr Soc 2009; 57 (11): 2085-2093.

FABBRINI G, et al. Fatigue in Parkinson's Disease motor or non-motor symptom? Parkinsonism Relat Disord 2013; v. 19, 148-52.

FAHN S, ELTON R, MEMBERS OF THE UPDRS DEVELOPMENT COMMITTEE. In: Fahn S, Marsden CD, Calne DB, Goldstein M, eds. Recent Developments in Parkinson's Disease, Vol 2. Florham Park, NJ. Macmillan Health Care Information 1987; 153-163, 293-304.

FERNANDEZ MC, et al. A pilot study on the impact of body composition on bone and mineral metabolism in Parkinson's disease. Parkinsonism and Related Disorders 2007; 13:355-358.

FINDLEY L, et al. Factors impacting on quality of life in Parkinson's disease: Results from an international survey. Mov Disord 2002;17:60-7.

FOLSTEIN, MF a practical method for grading the cognitive state of patients for the clinician. Journal of Psychiatry Research. 1975; Vol.12, 189 -198.

FORBES GB, REINA JC. Adult lean body mass declines with age: some longitudinal observations. Metabol 1970; 19: 653-63.

FOX KM, et al. Loss of bone density and lean body mass after hip fracture. Osteoporos Int 2000; 11: 31-35.

FRIEDMAN JH, et al. Fatigue rating scales critique and recommendations by the Movement Disorders Society task force on rating scales for Parkinson's disease. Mov Disord 2010; 25: 805-22.

FRIEDMAN JH, MILLMAN RP. Sleep disturbances and Parkinson's disease. CNS Spectr. 2008; 13(3 Suppl 4):12-7.

FRONTERA WR, et al. A cross sectional study of muscle strength and mass in 45to 78-yr-old men and women. J Appl Phys 1991; 71: 644-50.

GJERSTAD M, et al. Insomnia in Parkinson's disease: frequency and progression over time. J Neurol Neurosurg Psychiatry 2007; 78:476-9.

GOBBI LTB, et al. Núcleos da base e controle locomotor: aspectos neurofisiológicos e evidências experimentais. Revista Brasileira de Educação Física Especial 2006; v.20, n. 5, p. 97-101. 
GOEDERT M, et al. 100 years of Lewy pathology. Nat Rev Neurol 2013 ; 9:13-24.

GOETZ CG, et al. Movement Disorder Society-sponsored revision of the Unified Parkinson's Disease Rating Scale (MDS-UPDRS): process, format, and clinimetric testing plan. Mov Disord 2007; 22:41-7.

GOETZ CG, et al. Movement Disorder Society Task Force report on the Hoehn and Yahr staging scale: status and recommendations the Movement Disorder Society Task Force on rating scales for Parkinson's disease. Mov Disord 2004; 19:1020-8.

GOMES MM, QUINHONES MS, ENGELHARDT E. Neurophysiology of sleep and pharmacotherapeutic aspects of their disorders. Rev Bras Neurol. 2010; 46 (1): 5-15.

GOULART FO, et al. Fatigue in a cohort of geriatric patients with and without Parkinson's disease. Braz J Med Biol Res 2009; 42(8).

HAGELL P, BRUNDIN L. Towards an understanding of fatigue in Parkinson disease. J Neurol Neurosurg Psychiatr 2009; v. 80, p.489-92.

HALAVLIKOVA $E$, et al. Impact of fatigue on quality of life in patients with Parkinson's disease. Eur J Neurol 2008; 15:475-480.

HALLIDAY G, LEES A, STERN M. Milestones in Parkinson's Disease - Clinical and Pathologic Features. Mov Disord 2011; v. 26, n. 6, p. 1015-1021.

HAYLEY AC, et al. Excessive Daytime Sleepiness and Body Composition: A Population-Based Study of Adults. PLoS One 2014; Nov 10;9(11):e112238.

HOGLUND A, et al. Is excessive daytime sleepiness a separate manifestation in Parkinson's disease? Acta Neurol Scand. 2015; 132(2):97-104.

INKSTER, et al. Leg muscle strength is reduced in Parkinson's disease and relates to the ability to rise from a chair. Mov Disord. 2004; 18(2):157-62.

International Statistical Classification of Diseases and Related Health Problems, 10th revision. 2010. Available at: http://www.who.int/classifications/icd/en/. Accessed October 03, 2015.

IRWIN MR, COLE JC, NICASSIO PM. Comparative meta-analysis of behavioral interventions for insomnia and their efficacy in middle-aged adults and in older adults 55+ years of age. Health Psychol. 2006; 25 (1) 3-14.

JANKOVIC J. Parkinson's disease: clinical features and diagnosis $\mathrm{J}$ Neurol Neurosurg Psychiatry 2008; 79:368-376.

KIEBZAK GM, et al. Measurement precision of body composition variables using the Lunar DPX-L densitometer. J Clin Densitometry 2000; 3: 35-41. 
KINE B, et al. Excessive daytime sleepness in patients with Parkinson's Disease. CNS Drugs 2011; v. 25, p. 203-212.

KISTNER A, LHOMMÉE E, KRACK P. Mechanisms of body weight fluctuations in Parkinson's disease. Front Neurol 2014; 5:84.

KITAI E, et al. Fatigue as a First-Time Presenting Symptom Management by Family Doctors and One Year Follow-Up. Isr Med Assoc J. 2012;14(9):555-9.

KUMAR S, et al. Excessive daytime sleepiness in Parkinson's disease as assessed by Epworth Sleepiness Scale (ESS). Sleep Med 2003; 4:339-42.

KRANICK SM, DUDA JE. Olfactory dysfunction in Parkinson's disease. Neurosignals. 2008;16(1):35-40.

LANG AE, et al. Excessive daytime sleepiness and sudden onset sleep in Parkinson's disease: a survey from 18 Canadian Movement Disorders Clinics. Neurology 2001; 56(suppl 3):A307.

LANGSTON JW. The Parkinson's complex: parkinsonism is just the tip of the iceberg. Ann Neurol 2006; 59:591-6.

LATT MD. Why do people with Parkinson's disease fall? In: PhD thesis The University of Sydney; 2006.

LEES AJ, BLACKBURN NA, CAMPBELL VL. The nighttime problems of Parkinson's disease. Clin Neuropharmacol 1988; 11:512-9.

LEES AJ, HARDY J, REVESZ T. Parkinson's disease. Lancet 2009; v. 373, p. 20552006.

LEWY FH. Paralysis agitans. I. Pathologische Anatomie. In:Lewandowski M, ed. Handbuch der Neurologie, Band III. Berlin: Springer, 1912, 920-933.

LOHMAN, TG, ROCHE AF, MARTORELL R. Anthropometric standardization reference manual, Champaign, In: Human Kinetics, 1991.

MACHT M, et al. Predictors of freezing in Parkinson's disease: a survey of 6.620 patients. Mov Disord 2007; 22:953-6.

MAETZLER W, DREY M, JACOBS AH. Sarkopenie und Frailty in der Neurologie. Nervenarzt 2015; 86:420-430.

MANUAL DIAGNÓSTICO E ESTATÍSTICO DE TRANSTORNOS MENTAIS - DSM 5, 2013. 
MARTÍNEZ-MARTíN $P$, et al. Unified Parkinson's Disease Rating Scale characteristics and structure. Mov Disord 1994; 9 (1): 76-83.

MEHRHOLZ R, et al. Treadmill training for patients with Parkinson's disease. The Cochrane Database of Systematic Reviews 2010; n 1, Article ID CD007830.

MIGNOT, E. Why we sleep: the temporal organization of recovery. PloS Biol 2008; 6(4):e106.

NANA A, et al. Methodology Review: Using Dual-Energy X-ray Absorptiometry (DXA) for the Assessment of Body Composition in Athletes and Active People. Int J Sport Nutr Exerc Metab. 2015; Apr;25(2):198-215.

NEVITT MC. Risk factors for recurrent nonsyncopal falls. JAMA 1989; 261:26632668.

OBESO A. et al. The Basal Ganglia and Disorders of Movement: Patophysiological Mechanisms. News Physiological Science 2002; Vol.17, pp 51-55.

OLSON EJ, BOEVE BF, SILBER MH. Rapid eye movement sleep behaviour disorder: demographic, clinical and laboratory findings in 93 cases. Brain. 2000;123 (Pt 2):331-9.

PAVESE N, et al. Fatigue in Parkinson's Disease is linked to striatal and limbic serotonergic dysfunction. Brain 2010; v.133, p.3434-43.

PARKINSON J. An Essay on the Shaking Palsy. London: Sherwood, Neely and Jones, 1817.

PETRONI ML, et al. Body composition in advanced-stage Parkinson's disease. Acta Diabetol 2003; 40:S187-S190.

POEHLMAN ET, et al. Sarcopenia in aging humans: the impact of menopause and disease. J Gerontol A Biol Sci Med Sci 1995; 50:73-77.

POEWE W. Non-motor syntoms in Parkinson's Disease. European Journal of Neurology 2008; 15(suppl 1):14-20.

RAJPUT AH, et al. Course in Parkinson disease subtypes: a 39-year clinicopathologic study. Neurology 2009; 73:206-12.

RELJA M, MILETI'C V. Prevalence and awareness of non-motor symptoms in Parkinson's disease patients. Eur J Neurol 2010; 17(Suppl 3):377.

REIJNDERS JS, et al. A systematic review of prevalence studies of depression in Parkinson's disease. Mov Disord 2008; Jan 30;23(2):183-9; quiz 313. 
REVILLA M, et al. Body composition in Parkinson's disease: a study with dualenergy X-ray absorptiometry. Parkinsonism Relat Disord. 1998; Oct 4(3):137-42.

RILEY D, et al. Frozen shoulder and other shoulder disturbances in Parkinson's disease. J Neurol Neurosurg Psychiatry 1989; 52:63-6.

ROUBENOFF R, HUGHES VA. Sarcopenia: current concepts. J Gerontol ABiol Sci Med Sci 2000; 55:M716-724

RYE DB, JANKOVIC J. Emerging views of dopamine in modulating sleep/wake state from an unlikely source: Parkinson's disease. Neurology 2002; 58:341-6.

SCARAVILLI T, et al. Health-related quality of life and sleep disorders in Parkinson's disease. Neurol Sci 2003; 24(3): p. 209-10.

SCHAPIRA AH, TOLOSA E. Molecular and clinical prodrome of Parkinson disease: implications for treatment. Nat Rev Neurol 2010;6(6):309-317.

SCHENKMAN M, et al. Exercise for people in early- or mid-stage Parkinson disease: a 16-month randomized controlled trial. Phys Ther 2012; 92(11), 1395-1410.

SELIKHOVA M, et al. A clinico-pathological study of subtypes in Parkinson's disease. Brain 2009;132(Pt 11):2947-57.

SHULMAN LM, et al. Non-recognition of depression and other non-motor symptoms in Parkinson's disease. Parkinsonism Relat Disord 2002. 8(3): p. 193-7.

SHULMAN LM, De JAGER PL, FEANY MB. Parkinson's disease: genetics and pathogenesis. Annu Rev Pathol 2011;6:193-222.

SIDDIQUI MF, et al. Autonomic dysfunction in Parkinson's disease: a comprehensive symptom survey. Parkinsonism Relat Disord 2002; 8:277-84.

SILVA TAA, et al. Sarcopenia Associada ao Envelhecimento: Aspectos Etiológicos e Opções Terapêuticas Rev Bras Reumatol 2006; v. 46, n.6, p. 391-397.

SMITH WN, et al. Simple equations to predict concentric lower-body muscle power in older adults using the 30-second chair-rise test: a pilot study. Clin Interv Aging 2010; v. 5, p. $173-80$.

STAMEY WP, JANKOVIC J. Shoulder pain in Parkinson's disease. Mov Disord 2007. 22:S247-8.

STAVITSY $\mathrm{K}$, et al. The impact of sleep quality on cognitive functioning in Parkinson's disease. J Int Neuropsychol Soc. 2012; 18(1):108-17. 
STROCCHI $\mathrm{F}$, et al. Prevalence of fatigue in Parkinson disease and its clinical correlates. Neurology 2014; 83:215-220.

STRUCK LK, RODNITZKY RL, DOBSON JK. Circadian fluctuations of contrast sensitivity in Parkinson's disease. Neurology 1990; 40:467-70.

TANNER CM, Kamel F, Ross GW, et al. Rotenone, paraquat, and Parkinson's disease. Environ Helath Perspect 2011;119(6):866-72.

THOMAS C, et al. Fatigue: An Overview. Am Fam Physician 2008;78(10):1173-1179.

THOMAS J, NELSON J K. Métodos de Pesquisa em Atividade Física. $3^{\underline{a}}$ ed. Porto Alegre. 2002.

TOLOSA E, COMPTA Y, GIG C. The premotor phase of Parkinson's disease. Parkinsonism and relates Disorders 2007;13: S2-S7.

TRENKWALDER C. Sleep dysfunction in Parkinson's disease. Clin Neurosci 1998; 5(2): p. 107-14.

TOTH MJ, FISHMAN PS, POEHLMAN ET. Free-living daily energy expenditure in patients with Parkinson's disease. Neurology 1997; 48:88-91.

ULUSOY A, et al. Caudo-rostral Brain Spreading of alpha-Synuclein through Vagal Connections. EMBO Mol Med 2013; 5:1051-1059.

VISSER M, et al. Reliability and validity of the Beck depression inventory in patients with Parkinson's disease. Mov Disord 2006; 21(5):668-72.

YANG PY, et al. Exercise training improves sleep quality in middle-aged and older adults with sleep problems: a systematic review. J. Physiother 2012; 58 (3) 157-163.

YILMAZ O, et al. Evaluation of sarcopenia in Parkinson's disease [abstract]. Movement Disorders 2015; 30 Suppl $1: 4162$.

YORITAKA A. Sleep Disturbances in Parkinson's Disease. J Neurol Disord Stroke 2014; 2(2): 1043.

WANG P, et al. Hormone replacement therapy and Parkinson's disease risk in women: a meta-analysis of 14 observational studies. Neuropsychiatr Dis Treat. 2014; $11: 59-66$.

WEN H, et al. Epidemiology and clinical phenomenology for Parkinson's Disease with pain and fatigue. Parkinsonism Relat Disord 2012; v.18, S1, p.S222-S225.

WHITEHEAD L. The Measurement of Fatigue in Chronic Illness: A Systematic Review of Unidimensional and Multidimensional Fatigue Measures. J Pain Symptom Manage. 2009; 37(1):107-28. 
WILLIAMS DR, WATT HC, LEES AJ. Predictors of falls and fractures in bradykinetic rigid syndromes: a retrospective study. J Neurol Neurosurg Psychiatry 2006; 77:46873.

WICHMANN T, et al. Milestones in Research on the Pathophysiology of Parkinson's Disease. Mov Disord. 2011; 26(6): 1032-1041.

WOLTERS E. Variability in the clinical expression of Parkinson's disease. J Neurol Sci 2008; 266:197-203.

WOLTERS ECH, BRAAK H. Parkinson's disease: pre-motor clinico-pathological correlations. J Neural Transm 2006; (Suppl) 70:309-19.

ZOCCOLELLA S, et al. Sleep disorders and the natural history of Parkinson's disease: The contribution of epidemiological studies. Sleep Med Rev 2011; 15:41-50. 
Participante:

Data:

Data de nascimento:

Telefone:

Endereço:

Naturalidade: Procedência:

Escolaridade: Profissão:

Aposentado ( ) Ativo ( )

Quais os sintomas iniciais: Tremor ( ) Rigidez ( ) Lado:

Qual o $1^{\circ}$ diagnóstico (ex: fibromialgia, AVC,...) quando?

Data do diagnóstico da doença de parkinson:

Sintomas atuais: Lado: esq ( ) $\operatorname{dir}($ ) BILATERAL ( )

Tremor: ( ) sim ( ) não

( ) braço esquerdo

( ) perna esquerda

( ) braço direito

( ) perna direita

Rigidez: ( ) sim ( ) não

( ) braço esquerdo

( ) perna esquerda

( ) braço direito

( ) perna direita

Atividade física: ( ) sim

( ) não

Qual(is):

Onde:

Regular: ( ) sim ( ) não vezes por semana minutos Há meses / anos Medicações: 


\section{APÊNDICE B \\ Termo de Consentimento Livre e Esclarecido}

Você está sendo convidado(a) a participar, como voluntário(a), da pesquisa "Associação entre a composição corporal, fadiga e sonolência excessiva diurna em indivíduos com doença de Parkinson", cujo objetivo é verificar a influência da composição corporal sobre a fadiga e a sonolência excessiva diurna. Este projeto contém dois encontros. Nesses encontros, você passará por uma consulta médica com um neurologista e realizará um exame de composição corporal, além de preencher dois questionários.

Você receberá todos os esclarecimentos necessários antes e durante a pesquisa e lhe asseguramos que seu nome não será divulgado, sendo mantido o mais rigoroso sigilo com a omissão total de quaisquer informações que permitam identificá-lo(a). O seu transporte, se necessário, será feito pelo pesquisador responsável. O tempo de permanência no laboratório para a realização dos testes está estimado em duas horas e os horários de sua participação serão previamente agendados, respeitando os intervalos acima citados, bem como, a sua disponibilidade. Você deverá estar nos locais designados nos dias e horários marcados.

Com os resultados deste estudo poderemos obter informações sobre a influência da composição corporal sobre a sonolência e a fadiga, sendo este conhecimento útil aos profissionais da área da saúde. Os dados e materiais utilizados na pesquisa ficarão sob a guarda dos pesquisadores por um período de no mínimo cinco anos e após isso serão destruídos ou mantidos na instituição. As informações obtidas neste experimento poderão ser utilizadas como dados de pesquisa científica, podendo ser publicadas e divulgadas, sendo resguardada a sua identidade. Você poderá ter acesso aos seus resultados, por intermédio do pesquisador responsável.

A sua participação nesta pesquisa é voluntária, logo não haverá pagamento por sua colaboração. Você estará livre para negá-la ou para, em qualquer momento, desistir da mesma se assim desejar. No caso de aceitar fazer parte do estudo, após ter lido e sido esclarecido sobre as informações acima, você deverá assinar o final deste documento, que está em duas vias. Uma delas é sua e a outra ficará com o pesquisador responsável. Todas as folhas devem ser rubricadas pelo voluntário da pesquisa ou seu responsável e pelo pesquisador responsável.

Este projeto foi aprovado pelo Comitê de Ética em Pesquisa/ CAAE 39054214.6.0000.0030. Em caso de dúvida ou reclamação, você poderá entrar em contato com a pesquisadora responsável, Candice Alvarenga Coelho, (61) 34485280.

Eu declaro que

fui informado sobre os objetivos do estudo do Associação entre a composição corporal, fadiga e sonolência excessiva diurna em indivíduos com doença de Parkinson seus procedimentos, riscos e possíveis desconfortos. Ficou claro que a minha participação na pesquisa é isenta de despesas, que os dados coletados e acesso aos resultados são confidenciais e a obtenção de esclarecimentos é permanente. Concordo voluntariamente em participar desta pesquisa e que poderei anular 0 consentimento a qualquer momento, sem prejuízo, penalidade ou perda de qualquer benefício que eu tenha adquirido.

Assinatura do participante

Nome:

Endereço:
Data:

RG:

Telefone: ( )
CANDICE ALVARENGA COELHO
Data: 1 


\section{ANEXO I \\ ESCALA DE ESTADIAMENTO DE HOEHN e YAHR (HY) MODIFICADA}

Estágio 0: nenhum sinal da doença

Estágio 1: doença unilateral

Estágio 1,5: envolvimento unilateral e axial

Estágio 2: doença bilateral, sem comprometer o equilíbrio

Estágio 2,5: doença bilateral, com recuperação ao teste de puxar o paciente pelas costas

Estágio 3: doença bilateral de leve a moderada; alguma instabilidade postural; fisicamente independente.

Estágio 4: incapacidade grave; ainda capaz de andar e ficar ereto sem ajuda

Estágio 5: preso a cadeira de rodas ou ao leito necessita ajuda 


\section{ANEXO II \\ ESCALA DA SEVERIDADE DE FADIGA (ESF)}

Instruções: "Farei agora nove afirmações. Você deverá dar uma nota de 1 a 7 , onde 1 significa que você discorda completamente e 7 indica que você concorda plenamente com a afirmação. Lembre-se de que estas afirmações referem-se às suas duas últimas semanas."

1. Minha motivação é menor quando eu estou fatigado.

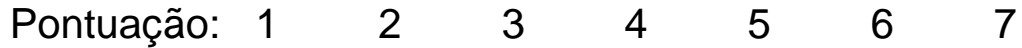

2. Exercícios me deixam fatigado.

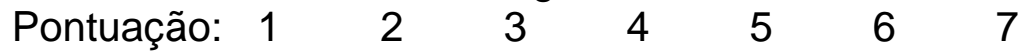

3. Eu estou facilmente fatigado.

Pontuação: $1 \quad 2 \quad 3 \quad 3 \quad 4 \quad 5 \quad 5 \quad 6 \quad 7$

4. A fadiga interfere com meu desempenho.

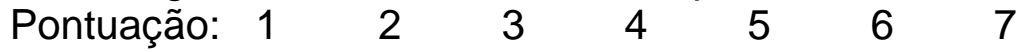

5. A fadiga causa problemas freqüentes para mim.

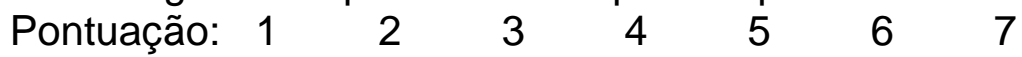

6. Minha fadiga impede um desempenho físico constante.

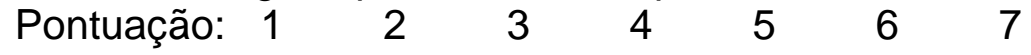

7. A fadiga interfere com a execução de certas obrigações e responsabilidades. Pontuação: $\begin{array}{lllllll}1 & 2 & 3 & 4 & 5 & 6 & 7\end{array}$

8. A fadiga é um dos três sintomas mais incapacitantes que tenho.

Pontuação: $1 \quad 2 \quad \begin{array}{lllllll}1 & 2 & 3 & 4 & 5 & 6 & 7\end{array}$

9. A fadiga interfere no meu trabalho, na minha família ou na minha vida social. Pontuação:

$\begin{array}{lllllll}1 & 2 & 3 & 4 & 5 & 6 & 7\end{array}$ 


\section{ANEXO III \\ ESCALA DE SONOLÊNCIA DE EPWORTH}

Qual é a probabilidade de você "cochilar" ou adormecer nas situações que serão apresentadas a seguir, em contraste com estar sentindo-se simplesmente cansado?

Isto diz respeito ao seu modo de vida comum, nos tempos atuais. Ainda que você não tenha feito, ou passado por nenhuma destas situações, tente calcular como poderiam tê-lo afetado. Utilize a escala apresentada a seguir para escolher o número mais apropriado para cada situação.

$0=$ nenhuma chance de cochilar

1 = pequena chance de cochilar

2 = moderada chance de cochilar

$3=$ alta chance de cochilar

\section{SITUAÇÃO CHANCE DE COCHILAR}

Sentado e lendo ( )

Vendo TV ( )

Sentado em um lugar público - ex. sala de espera, igreja ( )

Como passageiro de trem, carro ou ônibus; andando uma hora sem parar ( )

Deitando-se para descansar à tarde, quando as circunstâncias permitem ( )

Sentado conversando com alguém ( )

Sentado calmamente após almoço sem ter bebido álcool ( )

Se você tiver carro, enquanto para por alguns minutos quando pega trânsito intenso ( )

TOTAL 